\title{
OPEN Novel hypergravity treatment enhances root phenotype and positively influences physio-biochemical parameters in bread wheat (Triticum aestivum L.)
}

\author{
Basavalingayya K. Swamy ${ }^{1,4}$, Ravikumar Hosamani ${ }^{1,4 凶}$, Malarvizhi Sathasivam ${ }^{1}$, \\ S. S. Chandrashekhar ${ }^{2}$, Uday G. Reddy ${ }^{3}$ \& Narayan Moger ${ }^{1}$
}

Hypergravity-an evolutionarily novel environment has been exploited to comprehend the response of living organisms including plants in the context of extra-terrestrial applications. Recently, researchers have shown that hypergravity induces desired phenotypic variability in seedlings. In the present study, we tested the utility of hypergravity as a novel tool in inducing reliable phenotype/s for potential terrestrial crop improvement applications. To investigate, bread wheat seeds (UAS375 genotype) were subjected to hypergravity treatment (10×g for 12, and $24 \mathrm{~h}$ ), and evaluated for seedling vigor and plant growth parameters in both laboratory and greenhouse conditions. It was also attempted to elucidate the associated biochemical and hormonal changes at different stages of vegetative growth. Resultant data revealed that hypergravity treatment ( $10 \times g$ for $12 \mathrm{~h}$ ) significantly enhanced root length, root volume, and root biomass in response to hypergravity. The robust seedling growth phenotype may be attributed to increased alpha-amylase and TDH enzyme activities observed in seeds treated with hypergravity. Elevated total chlorophyll content and Rubisco $(55 \mathrm{kDa})$ protein expression across different stages of vegetative growth in response to hypergravity may impart physiological benefits to wheat growth. Further, hypergravity elicited robust endogenous phytohormones dynamics in root signifying altered phenotype/s. Collectively, this study for the first time describes the utility of hypergravity as a novel tool in inducing reliable root phenotype that could be potentially exploited for improving wheat varieties for better water usage management.

Gravity is the only constant fundamental force throughout the evolution of the Earth ${ }^{1}$, hence, all the living organisms are evolutionarily adapted to Earth's gravity $1 \times g$. Any deviation from Earth's gravity $(1 \times g)$ to either hypergravity or hypogravity causes a fundamental shift in physiology, structure, function, and behavior of organisms including plants ${ }^{2-6}$. Hypergravity is defined as a condition where the force of gravity is more than the Earth's gravity, and typically expressed as greater than one $(>1 \times g)$. Hypergravity conditions can be created by customized centrifuges that can precisely regulate acceleration values above $1 \times g$. It is reported that a hypergravity treatment can impart phenotypic, physiological, and structural benefits to plants ${ }^{7,8}$. For instance, carrot and rocket salad (Eruca sativa) seeds exposed to hypergravity $(7 \times g)$ significantly increased their germination rate, and seedling growth $^{8,9}$. Similarly, chronic hypergravity (at $10 \times g$ for 8 weeks) was reported to enhance the photosynthesis rate by increasing chloroplast size in Physcomitrella patens ${ }^{10}$. Interestingly, seeds exposed to hypergravity conferred salt stress resistance in carrot callus as evident by higher germination and seedling vigor index when compared to salt stress alone ${ }^{11}$.

Hypergravity by virtue of its mechanical loading reported imparting structural strength by manipulating cell wall properties and constituents in peas, cress, and azuki beans ${ }^{12-14}$. In contrast, wheat and rice seeds exposed to

${ }^{1}$ Institute of Agricultural Biotechnology (IABT), University of Agricultural Sciences, Dharwad, Karnataka 580005, India. ${ }^{2}$ Department of Seed Science and Technology, University of Agricultural Sciences, Dharwad, Karnataka 580005, India. ${ }^{3}$ AICRP on Wheat, University of Agricultural Sciences, Dharwad, Karnataka 580005, India. ${ }^{4}$ These authors contributed equally: Basavalingayya K. Swamy and Ravikumar Hosamani. ${ }^{\boxplus e m a i l:}$ hosamanirr@uasd.in 
acute hypergravity significantly reduced seedling growth, chlorophyll content, photosynthesis rate, transpiration rate, and stomatal conductance ${ }^{15-17}$. In another independent study, wheat seeds subjected to varied hypergravity intensity ( $500 \times g$ to $2500 \times g$ for $10 \mathrm{~min}$ ) have shown reversible effects including a recovery in germination, and seedling growth parameters in seeds stored for 6 days, and then sown ${ }^{17}$. More recently, maize seeds exposed to $1000 \times g$, for 2,4 , and $6 \mathrm{~h}$, exhibited enhanced germination and reduced seedling growth ${ }^{18}$. Thus, these studies indicate hypergravity can significantly induce variability among desired phenotypic traits in both vegetables and field crops. However, many of these studies were narrowly focused and restricted to the seedling stage only and no detailed studies from seedling through the greenhouse conditions from the prism of potential crop improvement have ever been tested.

Here we seek to investigate the utility of hypergravity as a novel tool for inducing desired phenotype/s and physiological traits that can be useful for the potential crop improvement program. To test this hypothesis, we choose wheat (Triticum aestivum L., family Poaceae), as it is being hailed as a major global cereal crop, provides staple food for about two billion people (36\% of the world's population) on Earth. In the present study, we carried out a screening study to reach the best intensity and duration that can induce desired phenotypic traits such as enhanced root length and associated phenotypes that may have relevance in drought avoidance or tolerance in wheat. Further, attempts were made to elucidate the biochemical basis including hormonal dynamics of this hypergravity-induced altered phenotype. To the best of our knowledge, this study reports for the first time the utility of hypergravity as a novel tool in inducing desirable phenotypic and physiological traits that have been evaluated for the entire life cycle-from germination to yield under greenhouse conditions for potential crop improvement application.

\section{Results}

Hypergravity screening studies resulted in optimum intensity and duration that induced significant phenotypic variations at the seedling stage in laboratory conditions. For the initial screening study, wheat seeds exposed to $2,5,10,20,50$, and $100 \times g$ for $12 \mathrm{~h}$ duration showed no significant changes in germination rate (79-80\%) in any of the above-tested hypergravity intensities. Interestingly, 2, 5, 10 and $20 \times g$ induced significant increase in root length by $17.00 \%(\mathrm{p}=0.015), 18.11 \%(\mathrm{p}=0.009), 28.31 \%(\mathrm{p}=0.000)$, and $17.48 \%(\mathrm{p}=0.012)$ respectively. In contrast, 50 and $100 \times g$ inhibited root length by $13.25 \%(\mathrm{p}=0.074)$ and $16.03 \%(\mathrm{p}=0.023)$ compared to control (Fig. 1A-C). Interestingly, the shoot length phenotype was significantly enhanced by $16.45 \%(\mathrm{p}=0.002)$ at $10 \times g$ only. However, at 50 and $100 \times g$, shoot length was significantly decreased by $23.72 \%(p=0.000)$ and $27.09 \%(p=0.000)$ respectively (Table 1$)$.

Having found the highest root and shoot length phenotypic response at $10 \times g$, it was decided to test various durations $-12,24,36,48,60$, and $72 \mathrm{~h}$ with a fixed intensity of $10 \times g$. Wheat seeds exposed to varied duration regimens resulted in no significant change in germination rate compared to control groups (79-80\%). Among the tested durations, 12, 24, 36 and $60 \mathrm{~h}$ induced a significant increase in root length by $21.72 \%(\mathrm{p}=0.000)$, $7.27 \%(\mathrm{p}=0.049), 4.77 \%(\mathrm{p}=0.059)$ and $10.52 \%(\mathrm{p}=0.003)$ respectively (Fig. 1D-F). Shoot length was increased by $11.49 \%(\mathrm{p}=0.048)$ only at $12 \mathrm{~h}$. In contrast, at $72 \mathrm{~h}$ time point, there was a significant decrease (by $11.60 \%$; $\mathrm{p}=0.045$ ) when compared to control in response to $10 \times g$ (Table 1 ). Collectively, a screening study revealed that $10 \times g$ intensity with 12 and $24 \mathrm{~h}$ duration was the best hypergravity regimen as it significantly enhanced root and shoot length in wheat at the seedling stage. Thus, this hypergravity regimen was chosen for all the follow-up studies in this investigation.

$10 \times g$ at 12 and $24 \mathrm{~h}$ regimen consistently resulted in changes in seedling vigor parameters at the seedling stage (8th-day) in laboratory conditions. To doubly ensure this altered phenotype at $10 \times g$, for 12 , and $24 \mathrm{~h}$, seven independent experiments with a total of 450 seedlings in each test group were evaluated in germination paper at the seedling stage-8th-day. Consistently as seen in the screening study, here also we found no significant change in germination rate (79-80\%) in response to $10 \times g$ for 12 and $24 \mathrm{~h}$. At $10 \times g$ for $12 \mathrm{~h}$ significantly enhanced root length $(25.47 \% ; \mathrm{p}=0.000)$, shoot length $(12.53 \% ; \mathrm{p}=0.041)$, and seedling vigor index (17.29\%; $\mathrm{p}=0.040)$ were observed. However, at $10 \times g$ for $24 \mathrm{~h}$ it was found that significant increase in only root length phenotype (14.62\%; $\mathrm{p}=0.009)$, and not shoot length and seedling vigor index (Fig. 1G-I, Table 1).

Additional experiments were conducted to gauze the time-course change in seed germination and root growth rate in laboratory condition. The temporal germination data indicates a significant change in germination rate in response to $10 \times g$ for $12 \mathrm{~h}$ treatment on day 2 only $(\mathrm{p}=0.035)$. Seedling growth rate recorded from first count (4th) to final count (8th day) of seedling stage indicates significant increase in root growth on 7 th $(p=0.003)$ and 8 th day $(\mathrm{p}=0.006)$ only. These data points suggest the critical time points to be looked at carefully to elucidate the molecular mechanism/s associated with the altered phenotype (Supplementary Fig. S2, Table S5).

Greenhouse study: seedling emergence and seedling vigor parameters in response to hypergravity recorded at the seedling stage-8th day. As a natural progression, altered phenotypes induced due to hypergravity treatment were further confirmed in greenhouse conditions in pots. In this study, two independent experiments with four internal replicates with a total of 80 seedlings on the 8th-day were evaluated for seedling emergence, root length, shoot length, seedling dry weight, and seedling vigor index. The $10 \times g$ at both the time point (12 and $24 \mathrm{~h}$ ) had no significant impact on seedling emergence $(90-95 \%)$ in the greenhouse condition. However, root length, shoot length, seedling dry weight and seedling vigor index were significantly enhanced by $19.58 \%(\mathrm{p}=0.000), 9.15 \%(\mathrm{p}=0.032), 10.52 \%(\mathrm{p}=0.049)$ and $13.73 \%(\mathrm{p}=0.027)$ respectively at $10 \times g$ for $12 \mathrm{~h}$ only compared to control. At $10 \times \mathrm{g}$ for $24 \mathrm{~h}$ time point no significant change in any of the tested parameters was observed (Fig. 2A-C, Table 2). 

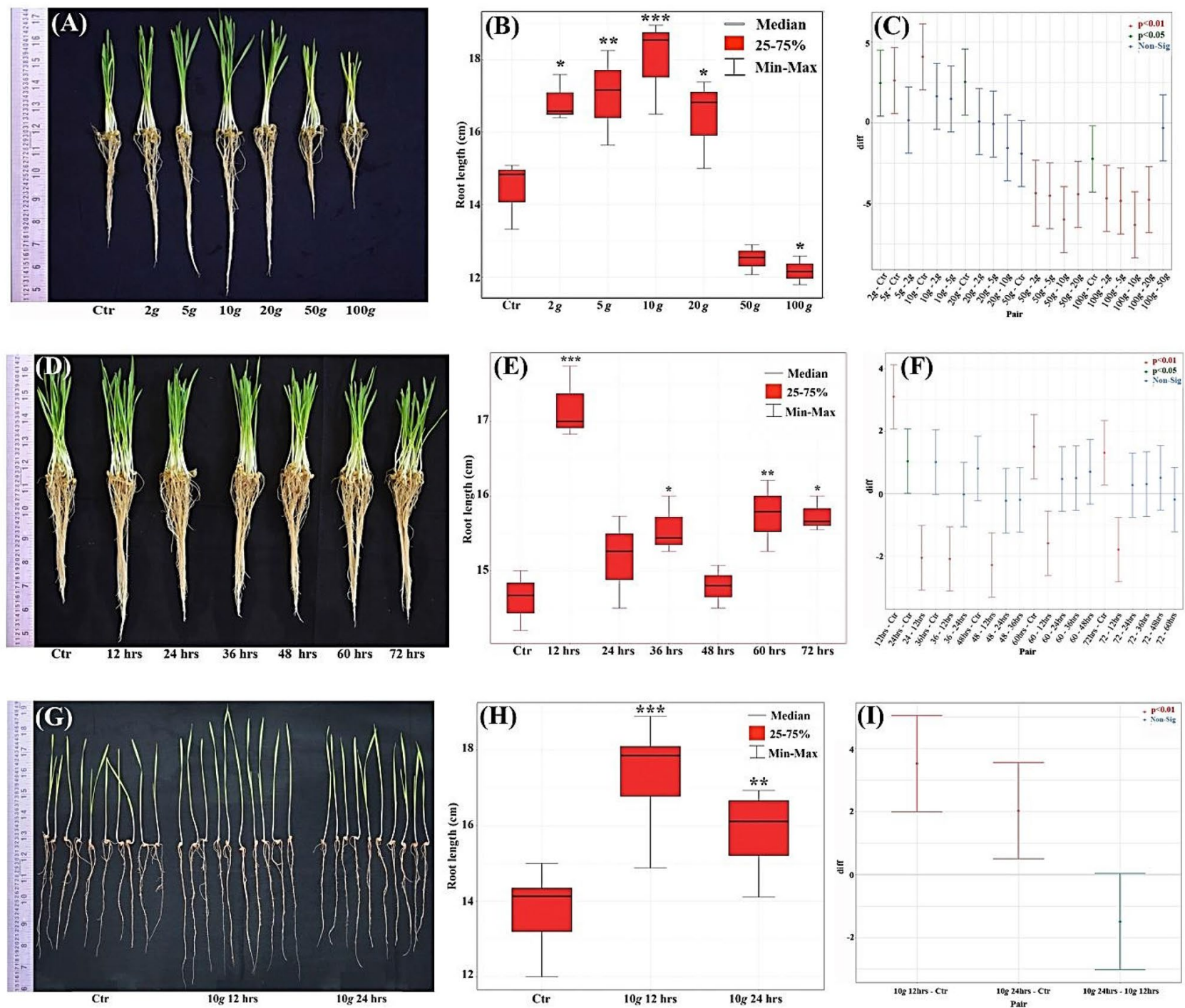

Figure 1. Screening for root and shoot phenotype in wheat using varied hypergravity intensity and duration at the seedling stage in laboratory condition using between-paper-method: (A) Qualitative image of root and shoot phenotype response to 2, 5, 10, 20, 50 and $100 \times g$ for a fixed duration of $12 \mathrm{~h}$; (B) Variability (red box plot) among seven treatments (Ctr; $2 \times g$; $5 \times g ; 10 \times g ; 20 \times g, 50 \times g$; 100×g) of root length phenotype; (C) Tukey plot with pairwise comparison with simultaneous $95 \%$ confidence level; (D) Qualitative images of root and shoot phenotype response to varied hypergravity durations-12, 24, 36, 48, 60 and $72 \mathrm{~h}$ for a defined intensity of $10 \times g$; (E) Variability (red box plot) among seven treatments (Ctr; $12 \mathrm{~h} ; 24 \mathrm{~h} ; 36 \mathrm{~h} ; 48 \mathrm{~h} ; 60 \mathrm{~h} ; 72 \mathrm{~h}$ ) of root length phenotype; (F) Tukey plot with pairwise comparison with simultaneous $95 \%$ confidence level; (G) Qualitative image of $10 \times g$, at 12 and $24 \mathrm{~h}$ treatment enhanced root length phenotype; (H) Variability (red box plot) among three treatments (Ctr; $10 \times g 12 \mathrm{~h} ; 10 \times g 24 \mathrm{~h}$ ) of root length phenotype; (I) Tukey plot with pairwise comparison with simultaneous $95 \%$ confidence level.

Seedling emergence and plant growth parameters in response to hypergravity recorded at the intermediate vegetative stage (20th-day). To assess the dynamic temporal changes in plant growth phenotypes in response to hypergravity, it was evaluated on the 20th-day-an intermediate vegetative phase of wheat in a pot experiment. In this study, along with seedling emergence, root, and shoot length, additionally, root volume, root dry weight, and shoot dry weight parameters were recorded. Specifically, at $10 \times g$, for $12 \mathrm{~h}$ time point, root length, and root dry weight were significantly increased by $18.01 \%(\mathrm{p}=0.018)$, and $25.55 \%$ $(\mathrm{p}=0.015)$ respectively when compared to control. In contrast, no such significant change was observed among these parameters at $24 \mathrm{~h}$ time point (Fig. 2D-F). Further, it was observed that shoot length and shoot dry weight were unaffected by the $10 \times g$ treatment at both 12 and $24 \mathrm{~h}$ (Table 2).

Seedling emergence and plant growth parameters in response to hypergravity recorded at the beginning of the reproductive stage (45th-day). In the pipe experiment, a total of 35 plants in each test group were divided into seven biological replicates for statistical reliability. In consistent with 20th- 


\begin{tabular}{|c|c|c|c|c|c|c|c|}
\hline & Hyper $g$ treatment & Mean \pm S. Em & $\%$ change over control & $\mathrm{P} \leq 0.05$ & Cal. F & CD (5\%) & CV (\%) \\
\hline \multirow{16}{*}{ Intensity screening study } & \multicolumn{7}{|l|}{ Root length (cm) } \\
\hline & Control $(1 \times g)$ & $14.41 \pm 0.549$ & & & \multirow{7}{*}{33.86} & \multirow{7}{*}{1.782} & \multirow{7}{*}{4.734} \\
\hline & $2 \times g$ & $16.86 \pm 0.370$ & 17 & $0.015^{*}$ & & & \\
\hline & $5 \times g$ & $17.02 \pm 0.756$ & 18.11 & $0.009^{*}$ & & & \\
\hline & $10 \times g$ & $18.49 \pm 0.281$ & 28.31 & $0.000^{*}$ & & & \\
\hline & $20 \times g$ & $16.93 \pm 0.232$ & 17.48 & $0.012^{*}$ & & & \\
\hline & $50 \times g$ & $12.50 \pm 0.237$ & -13.25 & 0.074 & & & \\
\hline & $100 \times g$ & $12.17 \pm 0.228$ & -16.03 & $0.023^{*}$ & & & \\
\hline & \multicolumn{7}{|l|}{ Shoot length $(\mathrm{cm})$} \\
\hline & Control $(1 \times g)$ & $11.55 \pm 0.279$ & & & \multirow{7}{*}{15.68} & \multirow{7}{*}{1.115} & \multirow{7}{*}{4.086} \\
\hline & $2 \times g$ & $12.15 \pm 0.256$ & 5.10 & 0.694 & & & \\
\hline & $5 \times g$ & $12.43 \pm 0.211$ & 7.53 & 0.295 & & & \\
\hline & $10 \times g$ & $13.45 \pm 0.384$ & 16.45 & $0.002^{\star}$ & & & \\
\hline & $20 \times g$ & $11.78 \pm 0.249$ & 1.90 & 0.996 & & & \\
\hline & $50 \times g$ & $08.81 \pm 0.168$ & -23.72 & $0.000^{*}$ & & & \\
\hline & $100 \times g$ & $08.43 \pm 0.253$ & -27.09 & $0.000^{*}$ & & & \\
\hline \multirow{16}{*}{ Duration screening study } & \multicolumn{7}{|l|}{ Root length (cm) } \\
\hline & Control $(1 \times g)$ & $14.25 \pm 0.226$ & & & \multirow{7}{*}{19.48} & \multirow{7}{*}{0.900} & \multirow{7}{*}{2.675} \\
\hline & $10 \times g 12 \mathrm{~h}$ & $17.35 \pm 0.270$ & 21.72 & $0.000^{*}$ & & & \\
\hline & $24 \mathrm{~h}$ & $15.29 \pm 0.245$ & 7.27 & $0.049^{*}$ & & & \\
\hline & $36 \mathrm{~h}$ & $14.93 \pm 0.187$ & 4.77 & 0.059 & & & \\
\hline & $48 \mathrm{~h}$ & $15.06 \pm 0.144$ & 5.63 & 0.181 & & & \\
\hline & $60 \mathrm{~h}$ & $15.75 \pm 0.274$ & 10.52 & $0.003^{\star}$ & & & \\
\hline & $72 \mathrm{~h}$ & $15.56 \pm 0.057$ & 9.14 & $0.010^{*}$ & & & \\
\hline & \multicolumn{7}{|l|}{ Shoot length $(\mathrm{cm})$} \\
\hline & Control $(1 \times g)$ & $10.60 \pm 0.297$ & & & \multirow{7}{*}{9.963} & \multirow{7}{*}{1.051} & \multirow{7}{*}{4.170} \\
\hline & $10 \times g 12 \mathrm{~h}$ & $11.81 \pm 0.496$ & 11.41 & $0.048^{*}$ & & & \\
\hline & $24 \mathrm{~h}$ & $10.41 \pm 0.011$ & -1.79 & 0.998 & & & \\
\hline & $36 \mathrm{~h}$ & $10.52 \pm 0.046$ & -0.75 & 1.000 & & & \\
\hline & $48 \mathrm{~h}$ & $10.22 \pm 0.161$ & -3.58 & 0.928 & & & \\
\hline & $60 \mathrm{~h}$ & $09.63 \pm 0.132$ & -9.15 & 0.156 & & & \\
\hline & $72 \mathrm{~h}$ & $09.37 \pm 0.234$ & -11.60 & $0.045^{*}$ & & & \\
\hline \multirow{12}{*}{ 8th day } & \multicolumn{7}{|l|}{ Root length (cm) } \\
\hline & Control $(1 \times g)$ & $13.82 \pm 0.304$ & & & \multirow{3}{*}{17.40} & \multirow{3}{*}{1.723} & \multirow{3}{*}{7.150} \\
\hline & $10 \times g 12 \mathrm{~h}$ & $17.34 \pm 0.541$ & 25.47 & $0.000^{*}$ & & & \\
\hline & $24 \mathrm{~h}$ & $15.84 \pm 0.392$ & 14.62 & $0.009^{*}$ & & & \\
\hline & Shoot length $(\mathrm{cm})$ & & & & & & \\
\hline & \begin{tabular}{|l|} 
Control $(1 \times g)$ \\
\end{tabular} & $12.53 \pm 0.333$ & & & & & \\
\hline & $10 \times g 12 \mathrm{~h}$ & $14.10 \pm 0.433$ & 12.53 & $0.041^{*}$ & 6.527 & 1.707 & 8.311 \\
\hline & $24 \mathrm{~h}$ & $13.42 \pm 0.477$ & 07.10 & 0.312 & & & \\
\hline & \begin{tabular}{|l|} 
Seedling vigor inde \\
\end{tabular} & & & & & & \\
\hline & Control $(1 \times g)$ & $2204 \pm 96.91$ & & & & & \\
\hline & $10 \times g 12 \mathrm{~h}$ & $2585 \pm 104.2$ & 17.29 & $0.040^{*}$ & 6.574 & 414.1 & 7.306 \\
\hline & $24 \mathrm{~h}$ & $2352 \pm 103.2$ & 6.72 & 0.570 & & & \\
\hline
\end{tabular}

Table 1. Varied hypergravity intensities and durations evaluated to determine the optimum intensity and duration that can induce desired phenotype/s in wheat seedlings in laboratory conditions using betweenpaper-method (Tab. F $(1 \%)=4.456$ (for intensity and duration study) and 6.013 (for 8th-day).

day plant growth phenotypes, on 45th-day also, root length and root-associated parameters were significantly enhanced in response to $10 \times g$, for $12 \mathrm{~h}$ only. In specific, at $10 \times g$, for $12 \mathrm{~h}$, root length (Fig. $2 \mathrm{G}-\mathrm{I}$ ), root dry weight (Fig. 2J), and root volume (Fig. $2 \mathrm{~K})$, were significantly enhanced by $21.93 \%(\mathrm{p}=0.000), 18.09 \%(\mathrm{p}=0.040)$, and $27.91 \%(\mathrm{p}=0.004)$, respectively when compared to control root, however, number of roots per plant increased but it was not statistically significant (Fig. 2L). In contrast, at $24 \mathrm{~h}$, no such significant change in root length and its associated parameters were observed. Further unlike, the 20th-day, at 45 th-day, shoot length phenotype was enhanced significantly by $11.64 \%(\mathrm{p}=0.012)$ at $10 \times \mathrm{g}$, for $12 \mathrm{~h}$ only. Although seedling emergence, number of tillers, number of roots, and shoot dry weight were recorded, but we found no significant change among these parameters in response to hypergravity at both the time points (Table 2). 

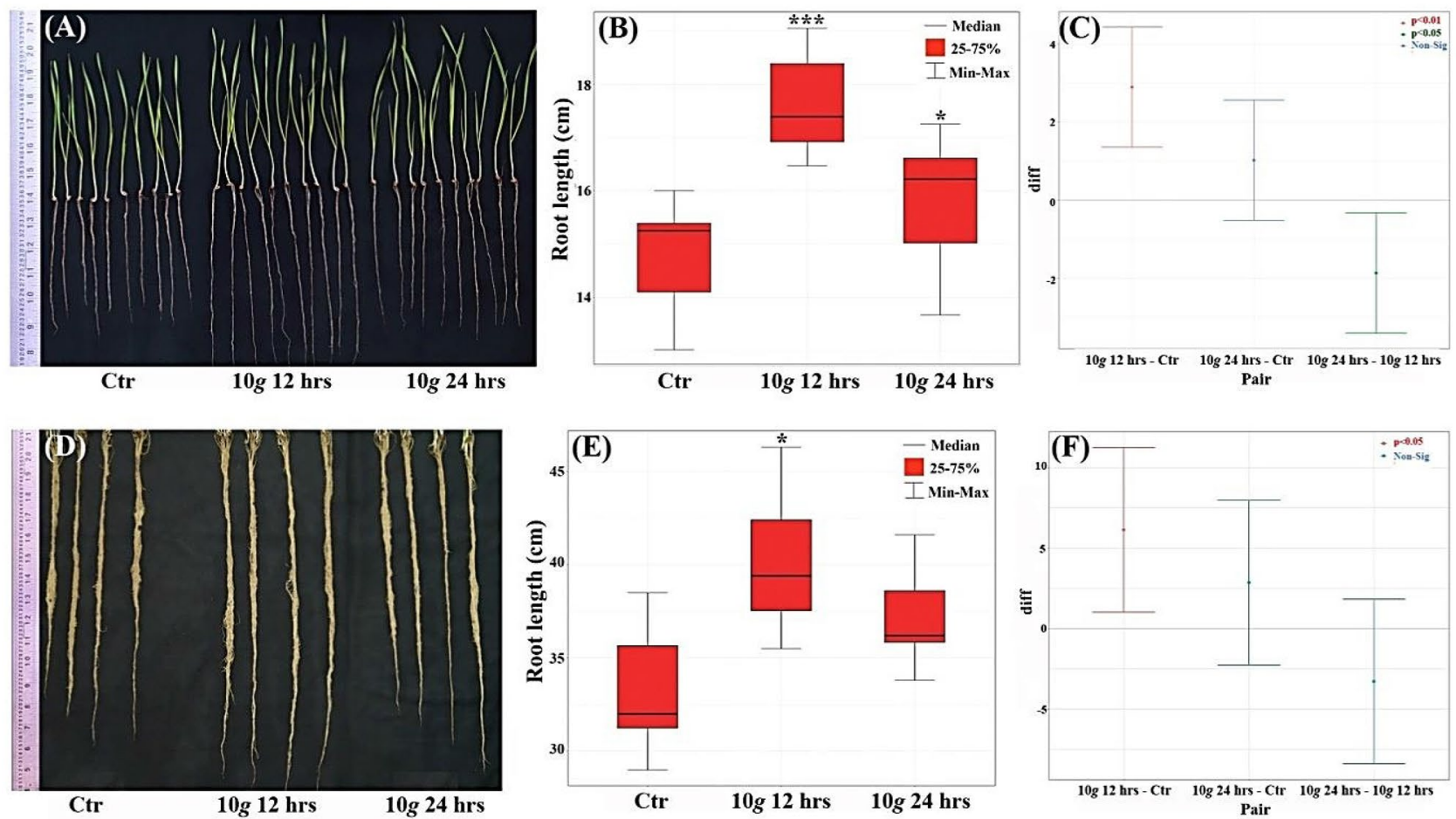

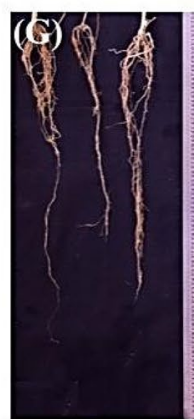

Ctr
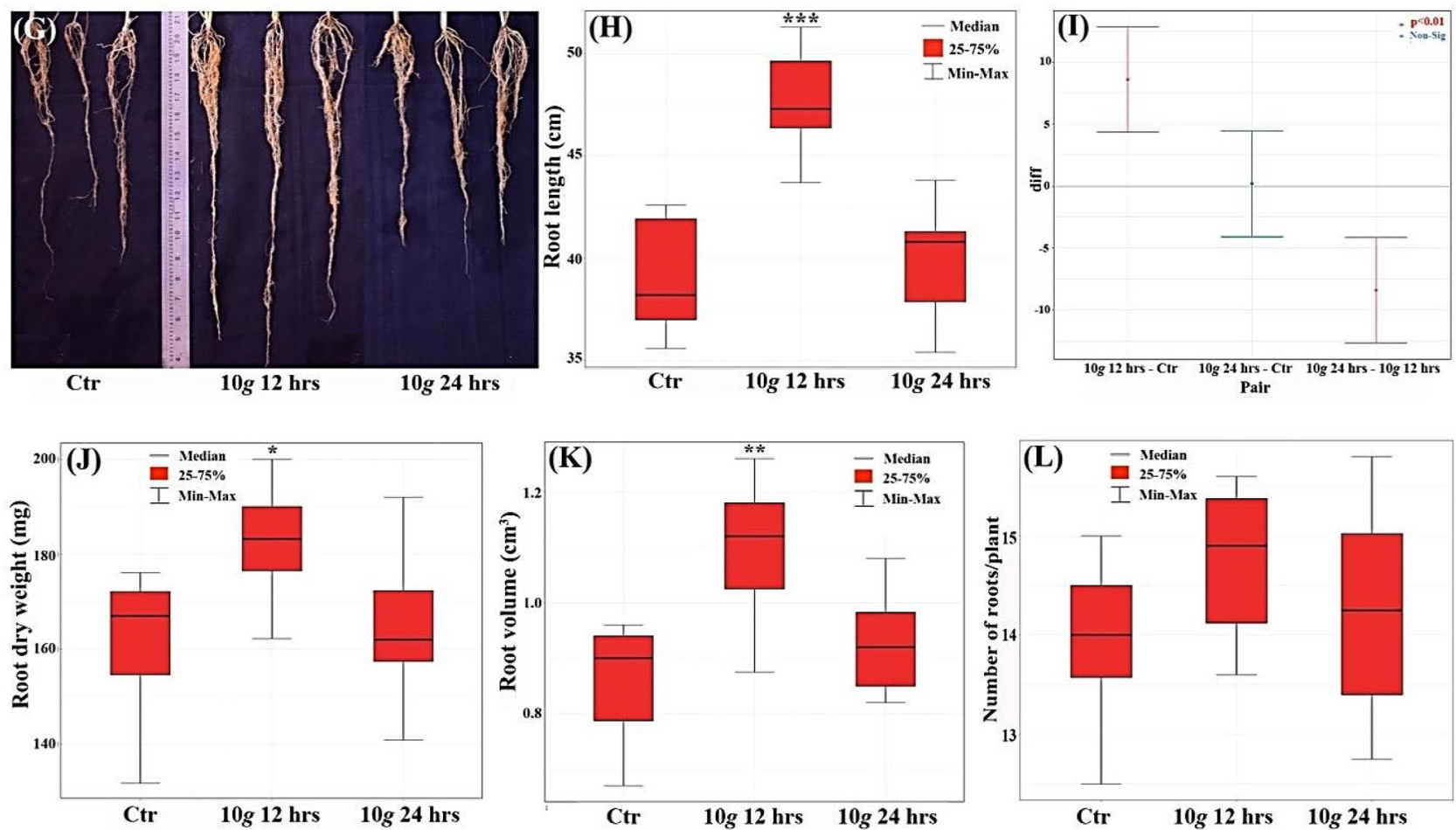

Figure 2. Hypergravity-induced ( $10 \times g$, for 12 and $24 \mathrm{~h}$ ) enhanced root phenotype recorded at 8 th, 20th and 45th-days in a greenhouse condition: (A) Qualitative image of root phenotype in response to hypergravity at seedling stage (8th-day); (B) Variability (red box plot) among three treatments (Ctr; $10 \times g$ 12 h; 10×g $24 \mathrm{~h}$ ) of root length phenotype; (C) Tukey plot with pairwise comparison with simultaneous 95\% confidence level; (D) Qualitative image of root phenotype in response to hypergravity at intermediate vegetative stage (20th-day); (E) Variability (red box plot) among three treatments (Ctr; $10 \times g 12 \mathrm{~h} ; 10 \times g 24 \mathrm{~h}$ ) of root length phenotype; (F) Tukey plot with pairwise comparison with simultaneous 95\% confidence level; (G) Qualitative image of root phenotype in response to hypergravity at the beginning of reproductive stage (45th-day); (H) Variability (red box plot) among three treatments (Ctr; $10 \times g 12 \mathrm{~h} ; 10 \times g 24 \mathrm{~h}$ ) of root length phenotype; (I) Tukey plot with pairwise comparison with simultaneous $95 \%$ confidence level; (J) Variability (red box plot) among three treatments (Ctr; $10 \times g$ 12 h; $10 \times g 24 \mathrm{~h}$ ) of Root dry weight; (K) Root volume in $\mathrm{cm}^{3}$; (L) Number of roots per plant recorded at 45 th-day. 


\begin{tabular}{|c|c|c|c|c|c|c|c|}
\hline & Hyper $g$ treatment & Mean \pm S. Em & $\%$ change over control & $\mathrm{P} \leq \mathbf{0 . 0 5}$ & Cal. F & CD (5\%) & CV (\%) \\
\hline \multirow{16}{*}{ 8th day } & \multicolumn{7}{|l|}{ Root length $(\mathrm{cm})$} \\
\hline & Control $(1 \times g)$ & $14.76 \pm 0.401$ & & & \multirow{3}{*}{11.83} & \multirow{3}{*}{1.268} & \multirow{3}{*}{7.032} \\
\hline & $10 \times g 12 \mathrm{~h}$ & $17.65 \pm 0.371$ & 19.58 & $0.000^{*}$ & & & \\
\hline & $24 \mathrm{~h}$ & $15.78 \pm 0.497$ & 6.91 & 0.235 & & & \\
\hline & \multicolumn{7}{|l|}{ Shoot length (cm) } \\
\hline & Control $(1 \times g)$ & $15.19 \pm 0.350$ & & & \multirow{3}{*}{4.059} & \multirow{3}{*}{1.057} & \multirow{3}{*}{5.892} \\
\hline & $10 \times g 12 \mathrm{~h}$ & $16.58 \pm 0.302$ & 9.15 & $0.032^{\star}$ & & & \\
\hline & $24 \mathrm{~h}$ & $16.18 \pm 0.406$ & 6.52 & 0.149 & & & \\
\hline & \multicolumn{7}{|c|}{ Seedling dry weight (mg) } \\
\hline & Control $(1 \times g)$ & $24.43 \pm 0.658$ & & & \multirow{3}{*}{3.667} & \multirow{3}{*}{2.116} & \multirow{3}{*}{7.339} \\
\hline & $10 \times g 12 \mathrm{~h}$ & $27.00 \pm 0.887$ & 10.52 & $0.049^{*}$ & & & \\
\hline & $24 \mathrm{~h}$ & $25.60 \pm 0.548$ & 4.79 & 0.489 & & & \\
\hline & \multicolumn{7}{|c|}{ Seedling vigor index } \\
\hline & Control $(1 \times g)$ & $2374 \pm 86.44$ & & & \multirow{3}{*}{4.593} & \multirow{3}{*}{240.3} & \\
\hline & $10 \times g 12 \mathrm{~h}$ & $2700 \pm 88.01$ & 13.73 & $0.027^{\star}$ & & & 8.324 \\
\hline & $24 \mathrm{~h}$ & $2638 \pm 66.43$ & 11.12 & 0.080 & & & \\
\hline & Root length $(\mathrm{cm})$ & & & & & & \\
\hline & Control $(1 \times g)$ & $34.03 \pm 1.612$ & & & & & \\
\hline & $10 \times g 12 \mathrm{~h}$ & $40.16 \pm 1.462$ & 18.01 & $0.018^{*}$ & 4.681 & 4.212 & 10.13 \\
\hline & $24 \mathrm{~h}$ & $36.86 \pm 1.136$ & 8.31 & 0.353 & & & \\
\hline & Shoot length (cm) & & & & & & \\
\hline & Control $(1 \times g)$ & $27.86 \pm 0.594$ & & & & & \\
\hline & $10 \times g 12 \mathrm{~h}$ & $28.21 \pm 0.924$ & 1.26 & 0.941 & 0.116 & 2.249 & 11.43 \\
\hline & $24 \mathrm{~h}$ & $27.71 \pm 0.714$ & -0.54 & 0.990 & & & \\
\hline & Root volume $\left(\mathrm{cm}^{3}\right)$ & & & & & & \\
\hline 20 th dox & Control $(1 \times g)$ & $0.38 \pm 0.039$ & & & & & \\
\hline $20 t n$ day & $10 \times g 12 \mathrm{~h}$ & $0.41 \pm 0.032$ & 6.32 & 0.093 & 1.293 & 0.099 & 18.06 \\
\hline & $24 \mathrm{~h}$ & $0.40 \pm 0.025$ & 5.26 & 0.872 & & & \\
\hline & Root dry weight (m & & & & & & \\
\hline & Control $(1 \times g)$ & $24.38 \pm 1.205$ & & & & & \\
\hline & $10 \times g 12 \mathrm{~h}$ & $30.61 \pm 1.430$ & 25.55 & $0.015^{*}$ & 5.003 & 4.202 & 13.74 \\
\hline & $24 \mathrm{~h}$ & $26.77 \pm 1.581$ & 9.80 & 0.479 & & & \\
\hline & Shoot dry weight (n & & & & & & \\
\hline & Control $(1 \times g)$ & $49.16 \pm 1.872$ & & & & & \\
\hline & $10 \times g 12 \mathrm{~h}$ & $52.59 \pm 1.301$ & 5.26 & 0.505 & 2.226 & 6.336 & 11.45 \\
\hline & $24 \mathrm{~h}$ & $46.25 \pm 2.905$ & -5.92 & 0.604 & & & \\
\hline & Root length (cm) & & & & & & \\
\hline & Control $(1 \times g)$ & $39.17 \pm 2.097$ & & & & & \\
\hline & $10 \times g 12 \mathrm{~h}$ & $47.76 \pm 2.982$ & 21.93 & $0.000^{*}$ & 17.25 & 3.512 & 13.43 \\
\hline & $24 \mathrm{~h}$ & $39.34 \pm 1.421$ & 4.07 & 0.995 & & & \\
\hline & Shoot length $(\mathrm{cm})$ & & & & & & \\
\hline & Control $(1 \times g)$ & $43.21 \pm 2.407$ & & & & & \\
\hline & $10 \times g 12 \mathrm{~h}$ & $48.24 \pm 2.202$ & 11.64 & $0.012^{*}$ & 18.94 & 1.410 & 12.76 \\
\hline & $24 \mathrm{~h}$ & $44.97 \pm 2.684$ & 4.10 & 0.083 & & & \\
\hline & Number of roots/ple & & & & & & \\
\hline 45 th dav & Control $(1 \times g)$ & $13.84 \pm 1.523$ & & & & & \\
\hline $45 \operatorname{cn}$ day & $10 \times g 12 \mathrm{~h}$ & $14.57 \pm 1.844$ & 5.31 & 0.699 & 0.332 & 1.898 & 11.88 \\
\hline & $24 \mathrm{~h}$ & $14.22 \pm 1.486$ & 2.73 & 0.908 & & & \\
\hline & Root volume $\left(\mathrm{cm}^{3}\right)$ & & & & & & \\
\hline & Control $(1 \times g)$ & $0.86 \pm 0.045$ & & & & & \\
\hline & $10 \times g 12 \mathrm{~h}$ & $1.10 \pm 0.050$ & 27.91 & $0.004^{*}$ & 7.883 & 0.130 & 12.11 \\
\hline & $24 \mathrm{~h}$ & $0.93 \pm 0.037$ & 8.14 & 0.549 & & & \\
\hline & Root dry weight (m & & & & & & \\
\hline & Control $(1 \times g)$ & $157.3 \pm 6.422$ & & & & & \\
\hline & $10 \times g 12 \mathrm{~h}$ & $185.8 \pm 7.193$ & 18.09 & $0.040^{*}$ & 4.641 & 20.69 & 10.91 \\
\hline & $24 \mathrm{~h}$ & $163.4 \pm 8.809$ & 3.87 & 1.000 & & & \\
\hline & & & & & & & \\
\hline
\end{tabular}




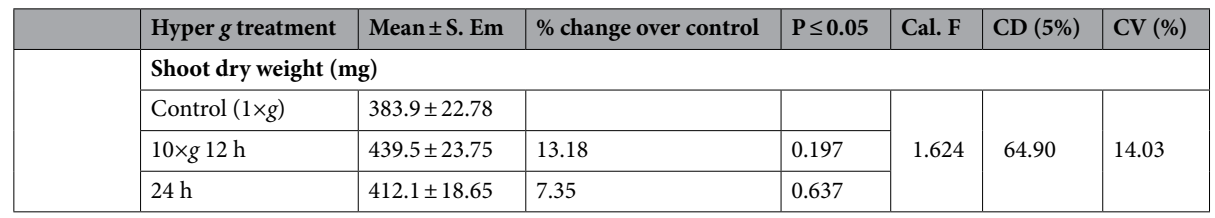

Table 2. Hypergravity-induced changes in wheat growth parameters recorded on the final count of wheat seedlings (8th-day), at intermediate vegetative growth stage (20th-day), and at the beginning of reproductive phase (45th-day) in greenhouse conditions (Tab. F $(5 \%)=3.555)$.

Collectively, from the above phenotypic data, root length and root-associated parameters such as root volume and root dry weight were consistently increased at $10 \times g$, specifically at $12 \mathrm{~h}$ regimen across different vegetative stages of wheat crop (8th, 20th, and 45th-day) in laboratory and greenhouse conditions.

Wheat seeds exposed to hypergravity resulted in a significant increase in $\alpha$-amylase, total dehydrogenase (TDH) activities, and altered seed protein profile. Since seedling vigor was significantly enhanced in response to hypergravity, we decided to investigate the underlying biochemical basis in terms of amylase and TDH activity and protein profile, specifically in seeds, post hypergravity exposure. In response to hypergravity $(10 \times g$ for $12 \mathrm{~h})$ treatment, $\alpha$-amylase activity was significantly enhanced by $13.57 \%(p=0.032)$ as evident from the increased mean diameter of the halo (clear) zone when compared to untreated seeds. However, at $24 \mathrm{~h}$, no significant change was observed (Fig. 3A,B). Similarly, TDH activity was also significantly enhanced by $22.4 \%(\mathrm{p}=0.003)$ at $10 \times g$, for $12 \mathrm{~h}$ only, with no significant change at $24 \mathrm{~h}$ when compared to control seeds (Fig. 3C).

SDS-PAGE (10\%) electrophorogram showed a marginal increase in the total number of wheat seed protein bands in response to hypergravity. In specific at $10 \times g$ for $12 \mathrm{~h}$, and $24 \mathrm{~h}$, nearly the same 25 protein bands (of $10-250 \mathrm{kDa}$ ) were found, whereas in control there were 23 protein bands, with a statistically significant difference among them (Fig. 3D). Further, the semi-quantitative band intensity of glutenin protein bands (approximately 67 and $57 \mathrm{kDa}$ ) that had shown qualitative changes in band intensity in response to hypergravity was analyzed using the ImageJ program. Interestingly, the $67 \mathrm{kDa}$ (Gluten) protein band intensity was specifically decreased by $7.3 \%(p=0.042)$ at $10 \times g$ for $12 \mathrm{~h}$ only when compared to control. No significant changes were observed in $24 \mathrm{~h}$ treatment group and $57 \mathrm{kDa}$ protein bands (Fig. 3D,E). Band intensity was expressed based on relative density after normalization with the control band, 1 (=100\%).

Hypergravity treatment enhanced total chlorophyll content and Rubisco protein expression quantified at 8th, 20th, and 45th-day of wheat growth in greenhouse conditions. Total chlorophyll content was estimated in all three vegetative growth stages-8th, 20th, and 45th-day in greenhouse conditions. On the 8 th and 20th-day, total chlorophyll content was significantly enhanced by $16.65 \%(p=0.001)$ and $12.29 \%(\mathrm{p}=0.014)$ respectively in response to $10 \times g$ for $12 \mathrm{~h}$ only, and no significant change was observed in $24 \mathrm{~h}$ treatment group. On the 45th day, although a marginal increase in total chlorophyll content $(8.23 \%$; $\mathrm{p}=0.252$ ) was observed at $12 \mathrm{~h}$, it was not statistically significant. It is interesting to note that as plant growth progressed from the seedling stage (day 8th) to the intermediate vegetative stage (day 20th) to the beginning of the reproductive phase (day 45th) there was a consistent decrease in percent change in total chlorophyll content over control. Further, as anticipated overall total chlorophyll content level increased as plant growth progressed in all the test groups (Fig. 3F).

Interestingly, quantification of Rubisco $(55 \mathrm{kDa})$ band intensity showed a significant increase by $11.5 \%$ $(\mathrm{p}=0.013)$ in response to hypergravity treatment $(10 \times g$ for $12 \mathrm{~h})$ at the 8 th-day seedling stage only when compared to control. However, Rubisco protein expression on the 20th and 45th-day showed a marginal increase in response to hypergravity, but it was not statistically significant (Fig. 3G,H; gel images were cropped and delineated with white space to separate the 8th, 20th, and 45th-day gels, and full-length gels are presented in Supplementary Fig. S1). It is interesting to note that, enhanced Rubisco $(55 \mathrm{kDa})$ protein at the seedling stage directly correlates with increased chlorophyll content observed in the present study. The band intensity was analyzed using the ImageJ program and expressed based on relative density after normalization with the control band, $1(=100 \%)$.

Hypergravity elicits robust phytohormones dynamics in the root. In the present study, 9 major endogenous hormone levels such as auxins, cytokinins, gibberellic acid (GA3), abscisic acid (ABA), salicylic acid (SA), and jasmonic acid (JA) and their derivatives were quantified using the LCMS method at 8th and 45th-day. Among the auxins, indole-3-acetic acid (IAA) was decreased by $38.26 \%(\mathrm{p}=0.002)$ in response to $10 \times \mathrm{g} 12 \mathrm{~h}$, whereas it was increased by $33.87 \%(\mathrm{p}=0.012)$ at $24 \mathrm{~h}$ when compared to control. In the case of indole-3-butyric acid (IBA), it was found to increase by $21.2 \%(\mathrm{p}=0.024)$ over control only at $10 \times g$ for $12 \mathrm{~h}$. Among the two tested cytokinins-benzyl aminopurine, and trans-zeatin riboside (ZR), only trans-zeatin riboside was enhanced significantly by $22.89 \%(\mathrm{p}=0.000)$ and $29.89 \%(\mathrm{p}=0.014)$ at $10 \times \mathrm{g}$ for 12 and $24 \mathrm{~h}$ respectively. Similarly, GA3 (gibberellic acid) response to hypergravity revealed interesting dynamism. For instance, GA3 concentration at $12 \mathrm{~h}$ was increased by $62.5 \%(\mathrm{p}=0.013)$, and at $24 \mathrm{~h}$ by $211.7 \%(\mathrm{p}=0.019)$ over control. Abscisic acid (ABA) response to hypergravity was significantly negative as evident from decreased concentration by $24.59 \%(\mathrm{p}=0.021)$ and $79.02 \%(\mathrm{p}=0.009)$ at $10 \times g$, for 12 , and $24 \mathrm{~h}$ respectively over control (Fig. 3I, Supplementary Table S2). Defense 
(A)

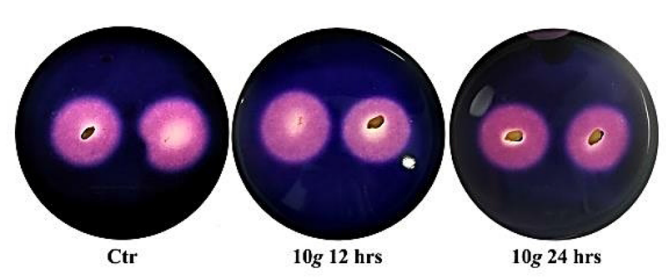

(D)

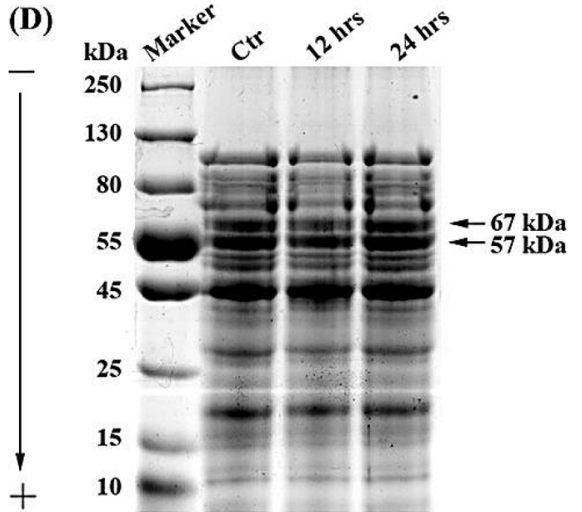

(F)

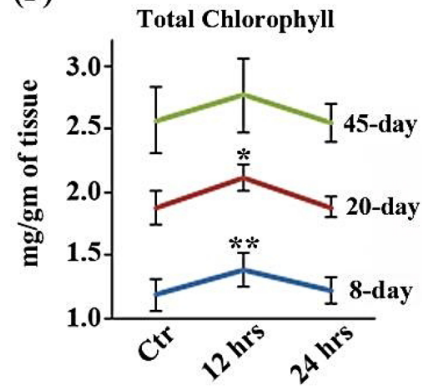

(I)

(G)

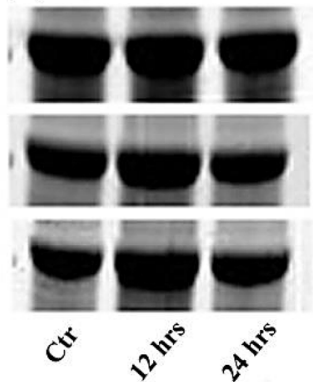

(B)

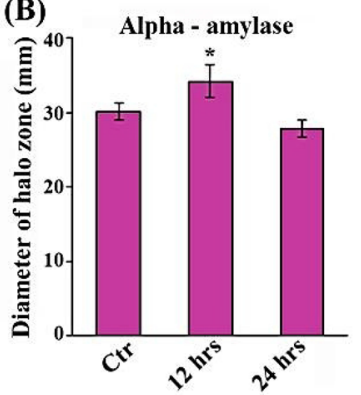

(E)
(C) Total dehydrogenase

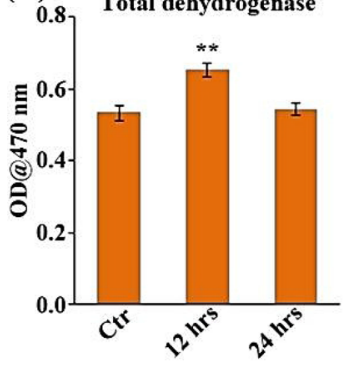

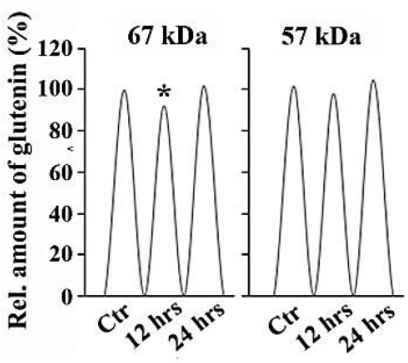

(H)

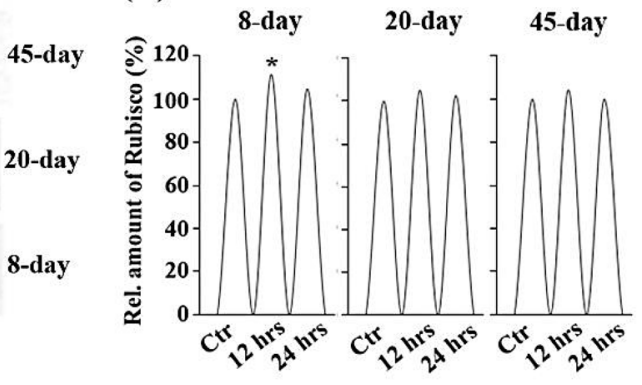

(J)

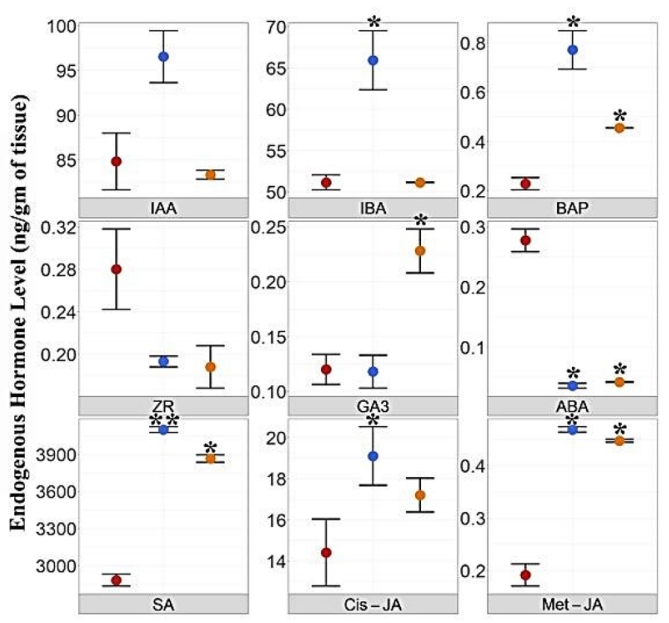

45-day 
4Figure 3. Biochemical parameters assayed post hypergravity treatment: (A) representative image of increased mean diameter of halo (clear) zone (in $\mathrm{mm}$ ) at $10 \times \mathrm{g} 12 \mathrm{~h}$ indicates significantly enhanced a-Amylase activity in wheat seeds in response to hypergravity; (B) Quantitative histogram of amylase activity; (C) significant increase in total dehydrogenase (TDH) activity in wheat seeds exposed to hypergravity; (D) SDS-PAGE (10\%) electrophorogram showing differential banding pattern of wheat seed proteins in response to hypergravity (Lane M: Marker, Lane 1: Control, Lane 2: $10 \times g 12 \mathrm{~h}$, Lane 3: $10 \times g 24 \mathrm{~h}$ ); (E) The qualitatively altered protein band intensity of selected two bands from SDS-PAGE run from wheat seeds exposed to hypergravity was quantified based on relative density; (F) A significant increase in total chlorophyll content from leaf tissue isolated from 8th, 20th and 45th-day old wheat plant grown in green house condition post hypergravity treatment; (G) Qualitative Rubisco protein band (Cropped and delineated with white space to separate out distinctly from 8th, 20th and 45th-day SDS-PAGE gels run from leaf tissue exposed to hypergravity and control) altered in response to hypergravity at 8 th, 20th and 45th-day, full-length gels are presented in Supplementary Fig. S1; (H) Quantitative band intensity of Rubisco protein band measured based on relative density; (I) Selected phytohormones response to hypergravity measured at 8th-day; (J) and 45th-day using UPLC by LC-MS/MS method.

hormones such as salicylic acid (SA), cis-jasmonate (cis-JA), methyl-jasmonate (met-JA) showed differential response to both 12 and $24 \mathrm{~h}$ of $10 \times \mathrm{g}$ exposure. While salicylic acid and cis-Jasmonate robustly enhanced by $47.06 \%(\mathrm{p}=0.033)$ and $791.7 \%(\mathrm{p}=0.000)$ respectively at a higher duration $(24 \mathrm{~h})$ only, methyl Jasmonate was found to be moderately increased by $17.29 \%(\mathrm{p}=0.001)$ and $16.54 \%(\mathrm{p}=0.049)$ at 12 and $24 \mathrm{~h}$ of $10 \times \mathrm{g}$ treatment respectively over control. Collectively, these stress hormones appear to respond more at $24 \mathrm{~h} 10 \times g$ treatment compared to $12 \mathrm{~h}$ implying sustained physiological stress imparted by the hypergravity at higher duration with a possible link to negative root phenotype (Fig. 3I, Supplementary Table S2).

Phytohormones quantified at the 45th day induced similar robust dynamics. The auxins such as 3-Indole acetic acid (IAA) and 3-Indole butyric acid (IBA) levels were increased by $13.80 \%(\mathrm{p}=0.194)$ and $28.91 \%(\mathrm{p}=0.031)$ in response to $10 \times g$ for $12 \mathrm{~h}$, whereas no significant change was observed at $24 \mathrm{~h}$ when compared to control. In the case of cytokinins-benzyl aminopurine (BAP), and trans-zeatin riboside (ZR), the BAP was enhanced significantly by $239.9 \%(\mathrm{p}=0.035)$ and $100 \%(\mathrm{p}=0.013)$ at $10 \times \mathrm{g}$ for 12 and $24 \mathrm{~h}$ respectively. Whereas the $\mathrm{ZR}$ was found to be decreased by $31.07 \%(p=0.115)$ and $32.68 \%(p=0.259)$ at $10 \times g$ for 12 and 24 h respectively when compared to control (Fig. 3J, Supplementary Table S3). Furthermore, the ABA level was significantly reduced by $86.82 \%(\mathrm{p}=0.004)$ and $84.66 \%(\mathrm{p}=0.008)$ at $10 \times \mathrm{g}$ for 12 and $24 \mathrm{~h}$ respectively over the control. The GA3 level was marginally decreased by $1.66 \%(\mathrm{p}=0.951)$ at $12 \mathrm{~h}$, while at $24 \mathrm{~h}$, it was significantly enhanced by $90 \%(\mathrm{p}=0.004)$ when compared to control. Interestingly, the defense hormones SA, cis-JA, and met-JA showed a similar enhanced response to $12 \mathrm{~h}$ and $24 \mathrm{~h}$ of $10 \times g$ exposure as that of 8 th-day root hormone dynamics. The salicylic acid was significantly enhanced by $42.26 \%(\mathrm{p}=0.000)$ and $34.15 \%(\mathrm{p}=0.006)$ at 12 and 24 h respectively. Similarly, the methyl-jasmonate was also robustly increased by $144.6 \%(\mathrm{p}=0.003)$ and $133.7 \%(\mathrm{p}=0.005)$ at 12 and $24 \mathrm{~h}$ of $10 \times g$ treatment respectively over control. Whereas the cis-jasmonate was found to be significantly increased by $32.57 \%(\mathrm{p}=0.002)$ at $12 \mathrm{~h}$ exposure only (Fig. 3J, Supplementary Table S3).

Hypergravity-induced delayed leaf senescence phenotype. Qualitative observation was taken on the 85th day of standing-crop in the pipe experiment under the greenhouse conditions suggests the delayed leaf senescence phenotype as indicated in the Fig. 4A-C. The qualitative images of plants indicated that hypergravity at $10 \times g$ exposed for 12 and $24 \mathrm{~h}$ retained green leaves longer after anthesis compared to control. The major endogenous hormone level relevant to delayed leaf senescence such as cytokinins (BAP and zeatin trans-isomer) and $\mathrm{ABA}$ were quantified in a shoot. Among the cytokinin-BAP and zeatin trans-isomer were significantly enhanced by $140 \%(\mathrm{p}=0.041)$ and $103.3 \%(\mathrm{p}=0.022)$ respectively at $10 \times g$ for $12 \mathrm{~h}$ exposure. In contrast, the ABA level was significantly reduced by $62.31 \%(\mathrm{p}=0.000)$ (Fig. $4 \mathrm{D}$, Supplementary Table $\mathrm{S} 4$ ).

Hypergravity treatment did not adversely influence yield traits. The selected yield-associated traits such as spike weight (gm), number of spikelets per spike, and 1000 seed weight (gm) were observed and no significant change was found in any of these parameters in response to hypergravity. Interestingly, spike length $(\mathrm{cm})$ significantly increased by $7.68 \%(\mathrm{p}=0.048)$ at $10 \times \mathrm{g}$ for $24 \mathrm{~h}$ treatment group when compared to control (Table 3).

\section{Discussion}

The present study explores the utility of hypergravity for inducing crop improvement traits both at the seedling and vegetative growth of the wheat in laboratory and greenhouse conditions. Initial screening studies identified the optimum hypergravity intensity and duration $(10 \times g$ at 12 and $24 \mathrm{~h}$ ) regimen that induced enhanced root length, root volume, and root dry weight in wheat. Change in these root traits specifically to $10 \times g$ for $12 \mathrm{~h}$, might have significantly stimulated columella cells in the root cap and triggered gravisensing signals for increased cell division or growth at the root tip. The gravisensing signal initiates with the physical information derived from the amyloplast sedimentation that can trigger signal transduction to change the direction of auxin transport in the cells. Upon reorientation in root columella cells, PIN-FORMED3 (PIN3), an auxin efflux carrier, re-localises to the bottom side of the cells ${ }^{19,20}$ resulting in the transport of auxin towards the lower side of the reoriented organs. Further, it has been shown that auxin develops an asymmetric distribution in young primary and lateral root tips due to the contributions of PIN3 and PIN7, resulting in a downward growth in response to altered gravity ${ }^{21}$. 


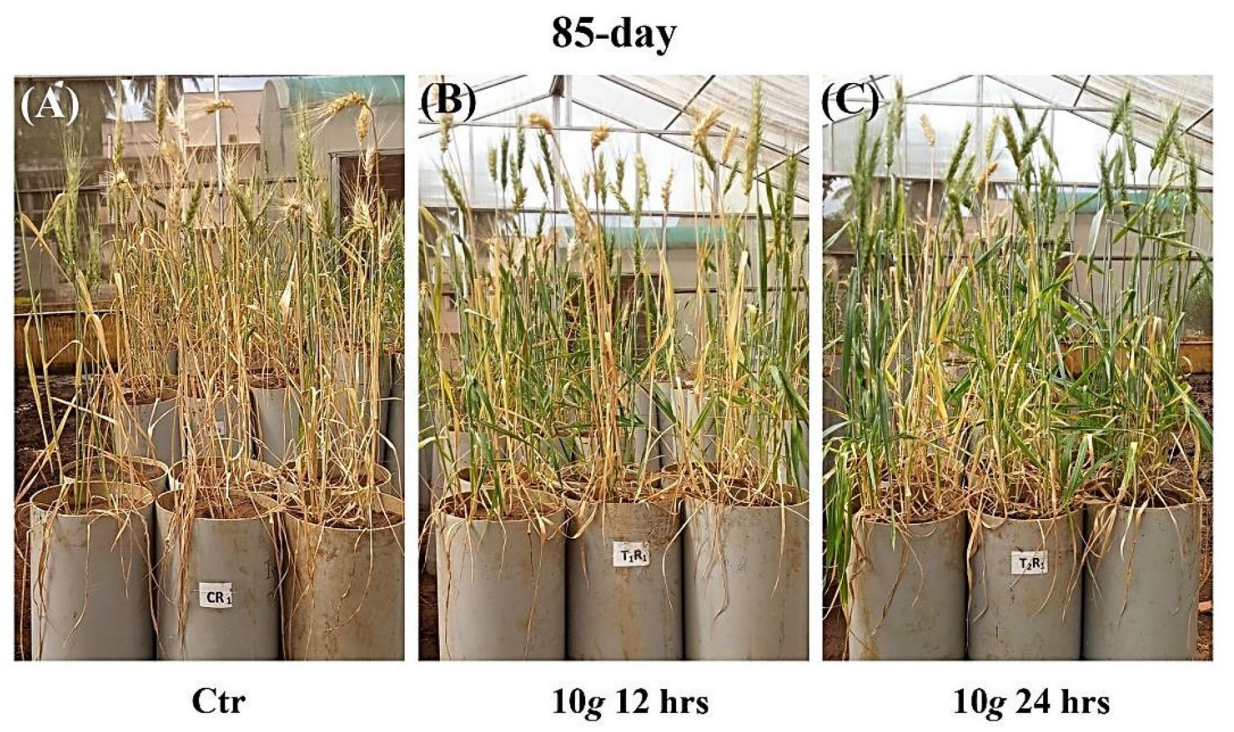

(D)

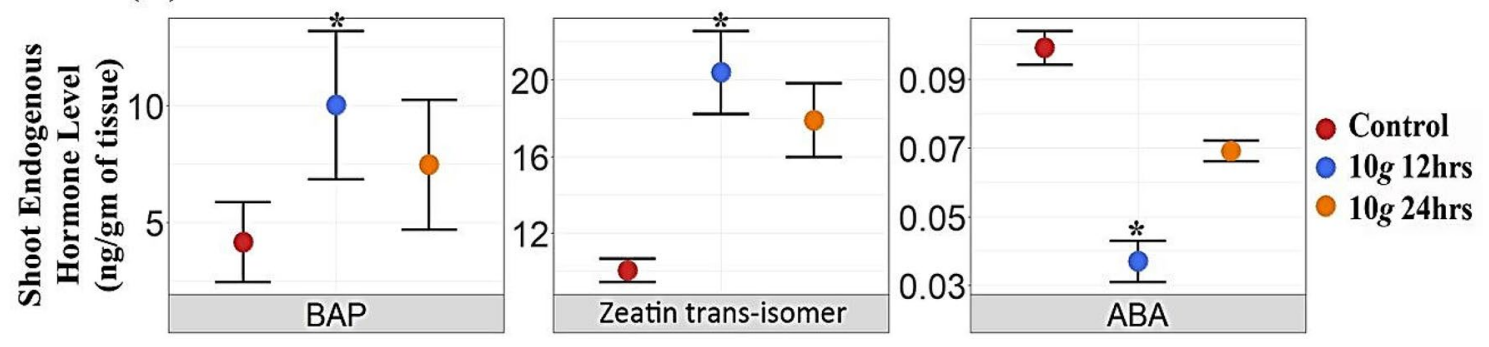

Figure 4. Delayed leaf senescence phenotype induced by hypergravity was observed in greenhouse experiment

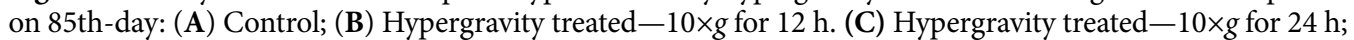
(D) Endogenous hormone levels in shoot.

However, higher hypergravity intensity and duration might have disrupted this signaling pathway leading to inhibition to hypergravitropic response beyond $10 \times g$ in the present study ${ }^{19}$.

Hypergravity being an added mechanical load; plant cells tend to compact structural components of the cell wall such as cellulose, matrix polysaccharide (hemicellulose and pectin) lignin, and reorientation of cortical microfibrils, thus, resulting in increased lateral growth and reduced longitudinal growth in various plants ${ }^{13,14,22,23}$. For instance, normal and de-capped Azuki bean seedlings under hypergravity conditions exhibited a decrease in the root growth ${ }^{24}$. Similarly, reduced root and shoot growth in wheat seedlings with increased gravity intensity (at $500 \times g$ to $2500 \times g$ for $10 \mathrm{~min}$ ) was reported ${ }^{25}$. In contrast, in the present study, wheat seeds exposed to $10 \times g$ for $12 \mathrm{~h}$ significantly enhanced root length and root volume consistently at seedling and across the different vegetative stages in greenhouse conditions. This differential phenotype can be attributed to the acute and chronic hypergravity protocol followed. Interestingly in the present study, root response to hypergravity was more consistent than shoot. This difference may be attributed to (1) size of vacuoles, unlike root columella cells that have many small vacuoles, shoot endodermal cells contain centrally located large vacuole that occupy $>90 \%$ of the total volume ${ }^{26}$. Hence, shoot endodermal cells may present a significant obstacle ${ }^{27}$ or restricts free fall of gravistimulated amyloplasts. (2) Presence of well-developed thylakoid membrane and photosynthetic pigments in addition to starch granules in shoot endodermal cells; whereas thylakoid membrane system within amyloplasts is completely absent in root columella cells. Lastly, (3) the difference in the arrangement of cytoskeletal structures, unlike root columella cells, shoot endodermal cells contain larger and more compact actin filaments ${ }^{28}$. Hence, compact actin filaments-mediated anchorage of their envelopes at the plasma membrane can prevent largescale gravity-dependent repositioning of organelles. Collectively, either one or combination of these factors can contribute to the less responsive nature of shoot to hypergravity stimuli compared to root.

Enhanced root length, root volume, root biomass were often correlated with the drought avoidance or tolerance through better water usage management mechanism specifically in rainfed wheat ${ }^{29-31}$. Increased root length was reported to enhance the volume of soil moisture that is available for capture, and root volume substantially increases root surface area and efficiently absorbs water, and imparts drought tolerance ${ }^{30}$. This trait becomes all the more important because wheat being predominantly a non-rainy season crop it needs to ensure better water usage management ${ }^{32}$. At $10 \times g$ for $12 \mathrm{~h}$, it was also observed that seedling vigor was significantly higher when compared to untreated seeds. Seedling vigor being a critical and yield-defining parameter, enhanced seedling vigor helps in establishing rapid, uniform germination, and robust seedling growth in diverse agro-climatic conditions. This can be partly attributed to the enhanced a-amylase and total dehydrogenase activities in the 


\begin{tabular}{|c|c|c|c|c|c|c|}
\hline Plant characters & Treatment & Mean \pm S. Em & $\%$ change over control & $P \leq 0.05$ & Cal. F (5\%) & CV (\%) \\
\hline \multirow{3}{*}{ Plant height $(\mathrm{cm})$} & Control $(1 \times g)$ & $47.39 \pm 1.01$ & & & \multirow{3}{*}{0.973} & \multirow{3}{*}{5.427} \\
\hline & $10 \times g 12 \mathrm{~h}$ & $49.31 \pm 1.01$ & 4.045 & 0.380 & & \\
\hline & $24 \mathrm{~h}$ & $48.71 \pm 0.95$ & 2.775 & 0.625 & & \\
\hline \multirow{3}{*}{ Number of tillers/plant } & Control $(1 \times g)$ & $04.57 \pm 0.20$ & & & \multirow{3}{*}{0.110} & \multirow{3}{*}{11.72} \\
\hline & $10 \times g 12 \mathrm{~h}$ & $04.59 \pm 0.18$ & 0.438 & 0.997 & & \\
\hline & $24 \mathrm{~h}$ & $04.70 \pm 0.21$ & 2.764 & 0.901 & & \\
\hline \multirow{3}{*}{ Spike length $(\mathrm{cm})$} & Control $(1 \times g)$ & $07.31 \pm 0.12$ & & & \multirow{3}{*}{3.612} & \multirow{3}{*}{6.12} \\
\hline & $10 \times g 12 \mathrm{~h}$ & $07.29 \pm 0.20$ & -0.234 & 0.997 & & \\
\hline & $24 \mathrm{~h}$ & $07.89 \pm 0.17$ & 7.684 & $0.048^{*}$ & & \\
\hline \multirow{3}{*}{ Spike weight (gm) } & Control $(1 \times g)$ & $01.17 \pm 0.07$ & & & \multirow{3}{*}{0.725} & \multirow{3}{*}{12.24} \\
\hline & $10 \times g 12 \mathrm{~h}$ & $01.19 \pm 0.04$ & 1.526 & 0.972 & & \\
\hline & $24 \mathrm{~h}$ & $01.26 \pm 0.04$ & 7.676 & 0.504 & & \\
\hline \multirow{3}{*}{ Spikelets/spike } & Control $(1 \times g)$ & $32.80 \pm 1.67$ & & & \multirow{3}{*}{0.148} & \multirow{3}{*}{13.41} \\
\hline & $10 \times g 12 \mathrm{~s}$ & $32.96 \pm 1.03$ & 0.474 & 0.998 & & \\
\hline & $24 \mathrm{~h}$ & $34.00 \pm 2.15$ & 3.643 & 0.872 & & \\
\hline \multirow{3}{*}{1000 Seeds weight (gm) } & Control $(1 \times g)$ & $25.94 \pm 0.84$ & & & \multirow{3}{*}{0.169} & \multirow{3}{*}{10.76} \\
\hline & $10 \times g 12 \mathrm{~h}$ & $26.81 \pm 1.54$ & 3.372 & 0.834 & & \\
\hline & $24 \mathrm{~h}$ & $26.27 \pm 0.54$ & 1.292 & 0.973 & & \\
\hline
\end{tabular}

Table 3. Hypergravity treatment did not adversely influence various yield traits (Tab. F $(5 \%)=3.555)$. Interestingly spike length at $10 \times g 24 \mathrm{~h}$ significantly increased by $7.68 \%(\mathrm{p}=0.048)$.

present study. Increased activities of these two enzymes enable rapid degradation of starch and soluble carbohydrates during seed germination and increased food and gas access to the developing embryos under hypergravity condition. Interestingly, Santos et al. ${ }^{8,9}$ and Nunes et al. ${ }^{33}$ reported similar robust seedling vigor phenotype upon hypergravity treatment in carrot and rocket salad $(7 \times g)$ and, eucalyptus and corymbia (at $7 \times g$ for $8 \mathrm{~h}$ and $1 \times g$ for the rest of $16 \mathrm{~h}$ for 9 days cycle; uninterrupted hypergravity at $7 \times g$ and $5 \times g$ for 8 and $24 \mathrm{~h}$ ) respectively.

In the present study, total chlorophyll content was significantly enhanced at $10 \times g$ for $12 \mathrm{~h}$ at the initial vegetative stage (8th and 20th-day) and a marginal increase at 45th-day. In line with the findings, Physcomitrella patens, a moss-grown in a chronic hypergravity environment (at $10 \times g$ for 8 weeks) revealed enhanced photosynthesis rate by increasing the chloroplast size ${ }^{10}$. In contrast, wheat seeds exposed to acute hypergravity treatments ranging from 500 to $2500 \times g$ for 10 min were reported to reduce chlorophyll content coupled with inhibited seedling growth ${ }^{15,34}$. These two contrasting findings may suggest the differential impact of acute and chronic hypergravity protocol. In leaf SDS-PAGE, a specific $55 \mathrm{kDa}$, Rubisco band (Ribulose-1,5-bisphosphate carboxylase/oxygenase) has shown significant changes in response to hypergravity. This data directly correlates with the increased chlorophyll content implying hypergravity treatment could physiologically benefit the wheat crop.

Seed protein electrophorogram revealed reduced selected band intensity. In general wheat seeds contain $80 \%$ gluten proteins with glutenin $(67-57 \mathrm{kDa})$ and gliadin $(44-36 \mathrm{kDa})$ as major fractions ${ }^{35}$. During germination and seedling growth, proteases present in the wheat seed embryo hydrolyze gluten proteins and provides an energy boost for radicle development ${ }^{36}$. Simultaneously, a-amylase and dehydrogenase activities will enhance with reduced gluten content ${ }^{37}$. In consistent with this, in response to hypergravity treatment wheat seeds exhibited increased alpha-amylase and total dehydrogenase enzyme activity coupled with reduced intensity of gluten protein bands. Specifically, the intensity of glutenin fractions ( 57 and $67 \mathrm{kDa}$ ) has reduced when compared to the control group. Thus, boosting the activities of alpha-amylase and TDH leading to enhanced seedling vigor (Fig. 3D).

Phytohormones play a critical role in the growth and morphogenesis of plants. Hence, we investigated the possible role of phytohormones in enhancing root length. Phytohormones profiling at both seedling (8th) and 45 thday-old root samples revealed robust dynamics. Among various phytohormones, the role of natural auxins such as indole-3-acetic acid (IAA) and indole-3-butyric acid (IBA) in regulating root growth are well documented ${ }^{38-40}$. It was reported that IAA strongly decelerates root elongation and the inverse relationship between the endogenous IAA level and root growth rate was confirmed in the elongation zone of maize roots ${ }^{41}$. In contrast, the endogenous level of indole-3-butyric acid (IBA) is shown to have a positive correlation with the regulation of root apical meristem size, root hair elongation, lateral root development, and formation of adventitious roots ${ }^{42}$. In consistent with this, the endogenous level of IAA was significantly reduced, and IBA concentration was increased in response to hypergravity in root samples. ABA is another interesting phytohormone reported to negatively regulate maize root growth similar to IAA ${ }^{43}$. Thus, a positive correlation of IBA and a negative correlation of IAA and ABA were observed with root phenotype.

Zeatin and its derivatives are the important groups of isoprenoid Cytokinins (CKs). Specifically, trans-zeatin riboside (ZR) was reported to possess an antagonistic interaction with ABA as non-hydraulic root-to-shoot signals in drought-stressed and re-watered sunflower plants ${ }^{44}$. In the present study, increased ZR and decreased ABA concentration were observed in response to hypergravity suggesting similar antagonistic interaction between them. A critical role of GA3 in breaking dormancy through the activity of alpha-amylase in rice seeds was 
reported ${ }^{45}$. Coincidentally, in the present study endogenous GA3 concentration and a-amylase activity were significantly enhanced in hypergravity $(10 \times g$ for $12 \mathrm{~h})$ treated seeds, suggesting a possible link of GA3 for enhanced $\alpha$-amylase activity leading to robust seedling vigor phenotype. The correlation between root phenotype and endogenous gibberellins (GAs) level can be partly explained by indeterminate effect exerted by gibberellins depending on the concentration as indicated in GA-deficient mutants or GA biosynthesis inhibiting studies ${ }^{46-50}$.

Inhibition of primary root growth by jasmonates is well documented ${ }^{51-53}$. However, it is also reported to influence lateral and adventitious root elongation in Arabidopsis and sunflower ${ }^{51,54}$. In consistent with this, jasmonates level was enhanced in response to $10 \times g$ for 12 and $24 \mathrm{~h}$, in which root growth was increased. This may suggest that a certain threshold of jasmonate is critically required for root elongation ${ }^{55}$. Another reason could be increased hypergravity-induced synergy between jasmonate and auxin signaling pathways promoting root regeneration by activating root stem cells as reported by Zhou et al. ${ }^{56}$. Similarly, the role of endogenous salicylic acid (SA) in the development of plant roots is relatively unknown. However, the concentration-critical influence of exogenous SA on root growth is reported. For instance, exogenous SA with $250 \mu \mathrm{M}$ inhibited Arabidopsis primary root growth and lateral root development ${ }^{57}$. In contrast, lower SA concentrations induced an increase in root length and biomass in corn at $1.5 \mu \mathrm{M}^{58}$, in soybean at $100 \mu \mathrm{M}^{59}$, and in mung bean between 200 and $400 \mu \mathrm{M}$. Based on this data, we speculate bioactive concentration window for endogenous SA to induce root growth is critical, and this may have played role in differential response to $10 \times g$ for 12 and $24 \mathrm{~h}$. Alternatively, robust changes in jasmonate and SA at $10 \times g$ for 12 and $24 \mathrm{~h}$ could be in response to hypergravity-induced physiological stress rather than a direct correlation with root phenotype. Because, jasmonate and SA alone or in combination are known to ameliorate stress conditions ${ }^{60}$, and hypergravity on the other hand is reported to induce such physiological stress in living organism/s including plants ${ }^{61}$.

Another interesting phenotype we observed in our study is delayed leaf senescence on the 85th-day. This phenotype was more prominent at $24 \mathrm{~h}$ than $12 \mathrm{~h}$ treatment group. It was reported that cytokinins and ABA are known to play a role in delaying leaf senescence in several plant species ${ }^{62}$. Hence, we decided to look at endogenous hormone levels specifically cytokinin and ABA in the shoot. Interestingly, at $12 \mathrm{~h}$ treatment, BAP, Zeatintrans isomer was significantly enhanced and ABA level was decreased in response to hypergravity, thus positively correlating the hormonal dynamics with observed phenotype. This delayed leaf senescence phenotype especially under water stress conditions is significant as it can help in maintaining the remobilization of stored nutrients in source-sink relationships leading to improved crop yield. Collectively, this study, for the first time, indicates that hypergravity can be exploited as a novel tool in inducing desirable phenotype/s and physio-biochemical parameters such as enhanced seedling vigor, root architecture, increased chlorophyll content, and delayed leaf senescence that can be potentially employed for the terrestrial crop improvement program. However, (1) the underlying molecular basis of this altered phenotype/s, (2) how this enhanced root and delayed leaf senescence phenotypes help in imparting drought tolerance, and (3) whether these altered phenotypes are genetically heritable needs to be addressed, and currently, our lab is investigating these questions.

\section{Methods}

Hypergravity exposure protocol. Hypergravity studies can be carried out using tabletop or floor model centrifuges with cup/tube holders to accommodate seeds. These laboratory centrifuges are in principle similar to the Large Diameter Centrifuge (LDC) facility located at ESTEC (ESA) research center in Noordwijk (The Netherlands) for hypergravity research ${ }^{63,64}$. For this study, we specifically used the floor model high-speed refrigerated centrifuge with a fixed angle rotor A-508C (Model 6000 Lot SER. NO. S40183-G000, Kubota Corporation, Tokyo, Japan). All the hypergravity experiments were carried out at $25{ }^{\circ} \mathrm{C}$ temperature maintained inside the centrifuge. Briefly, tubes containing a minimum of 100 good quality wheat seeds (variety UAS-375 were procured from AICRP, wheat scheme unit, University of Agricultural Sciences, Dharwad, Karnataka, India) were exposed to varied hypergravity intensity and durations by spinning at $10 \times g$ (300 rpm with the radius of rotor $10 \mathrm{~cm}$ ). The ' $\mathrm{g}$ ' force can be calculated using the relative centrifugal force (RCF). The RCF is computed by rotor speed and rotor radius of given centrifuge $\left[g=(1.118 \times 10-5) R \times S^{2}\right.$, where ' $R$ ' is the radius of the rotor in centimeters $(\mathrm{cm})$, ' $\mathrm{S}$ ' is the speed of the centrifuge in revolutions per minute $(\mathrm{rpm})$ and ' $g$ ' is the relative centrifugal force].

Phenotype screening study in laboratory conditions. The wheat seeds were exposed to varied hypergravity intensities such as $2,5,10,20,50$, and $100 \times g$ for $12 \mathrm{~h}$ to determine the best hypergravity intensity that can induce the desired seedling phenotype/s. To determine the best treatment duration $12,24,36,48,60$, and $72 \mathrm{~h}$ were evaluated. Multiple independent screening experiments were carried out to arrive at the best hypergravity intensity and duration. Based on the literature, to start with we considered desired phenotypes for this screening study were germination and seedling vigor phenotypes—root and shoot length.

Phenotype screening study in greenhouse conditions. The greenhouse experiments were conducted to confirm the hypergravity-induced changes using polythene bags for the 8th (final count of the seedling stage) and 20th-day (intermediate vegetative stage) studies. And PVC pipes (width 6 inches, 3 feet height) were used for the 45 th-day root study (i.e. beginning of the reproductive stage). The polythene bags $(50 \times 20 \mathrm{~cm})$ with uniformly mixed soil were sown with 8 seeds; two sides of bags were perforated to keep the soil, well-drained. The experiment was laid out in CRD (Completely Randomized Design) with four internal replications of each treatment including control. The same set of experiments was repeated four times for the 8th day's study, and two times for the 20th-day's study. Similarly, the plastic pipes with a width of 6 inches with 3 feet in height were used to confirm the hypergravity-induced changes in the wheat root phenotype specifically on the 45th-day. Both polythene bags and pipes were filled with sterilized sand, local black soil (the growth medium), and organic 
manure in 2:6:2 ratios respectively ${ }^{65}$. The bags/pipes were irrigated regularly with normal water to maintain soil moisture to field capacity. For the pipe experiment total of 12 sets, consisting of 6 pipes in each set was laid out in CRD in seven internal replications of each treatment group. In each pipe, 5 seeds were sown and later thinned out to 2 . The phenotypic observations, biochemical changes, and qualitative protein analysis were done on the 8 th, 20th, and 45th-days after sowing.

Germination rate (\%). The germination test was conducted with 100 seeds in each experiment by following the standard between-paper-method ${ }^{66}$.

Shoot and root length $(\mathrm{cm})$. Seedling vigor parameters such as shoot and root length were determined using standard protocols ${ }^{67,68}$.

Seedling vigor index. The seedling vigor index was computed by adopting the method suggested by Abdul Baki and Anderson $(1973)^{69}$ and expressed as an index number. Seedling vigor index $=$ Germination $(\%) \times[$ Root length $(\mathrm{cm})+$ Shoot length $(\mathrm{cm})]$.

Seedling dry weight $(\mathrm{mg})$. The same set of wheat seedlings used for measuring root and shoot length were kept in butter paper and dried in a hot-air oven maintained at $70{ }^{\circ} \mathrm{C}$ temperature for $24 \mathrm{~h}$. Then, the seedlings were allowed to cool in a desiccator for $20 \mathrm{~min}$ and the average weight was calculated and expressed in milligram per seedling ${ }^{70}$.

A number of roots per plant and root volume $\left(\mathrm{cm}^{3}\right)$. These two parameters were taken only on the 45th-day. The number of fibrous roots arising from the base of the plant and penetrated the soil was counted as per the standard $\operatorname{protocol}^{70}$.

Physio-biochemical parameters. Alpha-amylase and total dehydrogenase (TDH) activities in seeds. The $\alpha$-amylase activity was analysed as per the method suggested by Simpson and Naylor ${ }^{71}$. Briefly, the pre-soaked (for $8 \mathrm{~h}$ ) and half-cut seeds were placed on the agar media in such a way that the endospermic part remained in contact with the agar-starch gel. After $48 \mathrm{~h}$ of incubation at $30^{\circ} \mathrm{C}$ in the dark, potassium iodide solution was uniformly smeared on agar media. After a few minutes, the diameter of the halo (clear) zone formed around the seed was measured in millimetres $(\mathrm{mm})$ and represented as an $\alpha$-amylase activity.

For assessing total dehydrogenase activity the excised embryos from twenty-five random seeds from each treatment group were steeped into 0.25 percent solution of 2,3,5-triphenyl tetrazolium chloride, and incubated in dark for two hours at $40^{\circ} \mathrm{C}$ for staining. The stained seeds were washed with water, then soaked in $10 \mathrm{ml}$ of 2 methoxy ethanol (methyl cellosolve), and incubated overnight for extracting the red formazan color. The intensity of red color was measured using a UV-Vis spectrophotometer at $470 \mathrm{~nm}$, and methyl cellosolve was used as a blank. The resultant OD value is represented as total dehydrogenase activity ${ }^{72}$.

Total chlorophyll estimation at 8th, 20th, and 45th day. Different photosynthetic pigments such as chlorophyll a, chlorophyll b., and total chlorophylls were estimated using protocol suggested by Bames et al. ${ }^{73}$. Briefly, $0.1 \mathrm{~g}$ of fresh leaf samples were placed in a test tube containing $10 \mathrm{ml}$ of DMSO and incubated overnight. The chlorophyll extracted into the DMSO solution was collected, and the concentration of chlorophyll a, b, and total chlorophyll were quantified using UV-Vis spectrophotometer at $645 \mathrm{~nm}$ and $663 \mathrm{~nm}$ using the following formula and represented in $\mathrm{mg}$ chl./g of tissue.

$$
\begin{aligned}
& \text { mg chl. a } / g \text { tissue }=12.7(\text { A 663 })-2.69(\text { A } 645) \times[V /(1000 \times W)], \\
& \text { mg chl. b/g tissue }=22.9(\text { A } 645)-4.68(\text { A } 663) \times[\mathrm{V} /(1000 \times \mathrm{W})], \\
& \text { mg total chl. } / g \text { tissue }=20.2(\text { A } 645)+8.02(\text { A } 663) \times[V / 1000 \times W)] .
\end{aligned}
$$

where $\mathrm{A}=$ Absorbance at a specific wavelength, $\mathrm{V}=$ Final volume of chlorophyll extract in DMSO, $\mathrm{W}=$ Fresh weight of tissue extracted.

Profiling of phytohormones by LCMS: extraction and LC and MS-MS run conditions. The phytohormone profiling study was carried out using the extraction procedure for different plant hormones as described by Pan et al. ${ }^{74}$. Briefly, A known quantity ( $3 \mathrm{gm}$ ) of the sample was homogenized using 1-propanol/ $\mathrm{H}_{2} \mathrm{O}$ /concentrated $\mathrm{HCl}\left(2: 1: 0.002\right.$, v/v/v), sonicated for $30 \mathrm{~min}$ at $4{ }^{\circ} \mathrm{C}$, and incubated overnight. The next day, dichloromethane was added to the homogenate, sonicated for $30 \mathrm{~min}$, and then centrifuged at 12,000 rpm for $10 \mathrm{~min}$. Post centrifugation, the bottom aqueous layer was transferred to a conical flask containing sodium sulfate to remove the water traces using a flash evaporator. The dried samples were dissolved in $80 \%$ methanol and loaded the sample through C-18 solid-phase extraction (SPE) cartridges to UPLC. The extract is loaded on the preconditioned column and eluted using methanol. The eluted hormones were $(5 \mathrm{ml})$ evaporated to dryness using a flash evaporator with a water bath temperature of $35^{\circ} \mathrm{C}$ and dissolved in $500 \mu \mathrm{l}$ methanol- $0.05 \%$ formic acid $(1: 1 \mathrm{v} / \mathrm{v})$. The filtered solution was injected into LCMS. The flow rate was maintained at $0.2 \mathrm{ml} / \mathrm{min}$ in the analytical column with $25^{\circ} \mathrm{C}$ temperature $(2.1 \times 50 \mathrm{~mm}$ UPLC BEH-C18 column (Waters, USA) with $1.7 \mu \mathrm{m}$ particles, and protected by a vanguard $2.1 \times 5 \mathrm{~mm} \mathrm{BEH} \mathrm{C-18}$ with $1.7 \mu \mathrm{m})$. The eluted hormones were identified 
and quantified by using an LC-MS/MS (Waters-Acquity, USA) system by comparing the internal standards. For internal standards, all the standard hormones (technical grade) were procured from Sigma-Aldrich and tuned into Mass spectroscopy based on their mass and developed a standard-protocol as follows. Briefly, different concentrations of standard hormones were prepared and injected into LC-MS. From the respective peak area and concentration, the calibration curve was made for each plant hormone and arrived at the standard value ( 1 peak area $=\mathrm{x} n g$ ). Later test samples were injected, based on the retention time and mass (particular peak), the hormones were identified and quantified using the standard value and expressed in $\mathrm{ng} / \mathrm{g}$ of the sample weight. The hormone standards were listed in Supplementary Table S1.

Qualitative analysis of associated temporal protein changes in response to hypergravity. The qualitative analysis of protein changes associated with hypergravity treatment was carried out using SDS-PAGE. The SDS-PAGE was run with hypergravity treated seeds and leaves obtained from different stages of plant growth on the 8th, 20th, and 45th-day to assess the temporal changes in Rubisco (55 kDa) protein level. The resultant qualitatively altered protein band intensity of selected bands from SDS-PAGE run from wheat seeds and leaf tissue obtained post hypergravity treatment was quantified based on relative density. From leaf tissue SDS-PAGE, specifically, Rubisco protein band cropped from 8th, 20th, and 45th-day SDS-PAGE gels were quantified based on relative density. The experiment was performed with three independent biological replications for statistical reliability. The detailed method of protein extraction ${ }^{75}$, quantification ${ }^{76}$, and SDS-PAGE were carried out as per the standard protocols ${ }^{77}$.

Yield parameters. To quantify the yield traits at the maturity stage, five plants were taken from each replication and seven independent biological replicates with a total of 35 plants for each group were used. The yield traits such as spike length $(\mathrm{cm})$, spike weight $(\mathrm{gm})$, number of spikelets per spike, and thousand-grain weight (gm) were recorded as per the standard protocols ${ }^{78}$.

Statistical analysis. All the data generated in this research was at least in triplicates for statistical reliability. The resultant data were subjected to one-way ANOVA with CD at both $1 \%$ and $5 \%$ level of significance and followed by a post hoc Tukey test to establish multiple pair-wise comparisons using 'SPSS version 20.0' and ' $\mathrm{R}$-version 4.0.2 ${ }^{\prime 79}$ software (http://www.R-project.org/). The data collected from the biochemical and qualitative protein analysis experiments were subjected to the independent variable ' $\mathrm{T}$ ' test.

Ethical approval. Wheat seeds (UAS-375 genotype) collected from AICRP on Wheat, University of Agricultural Sciences, Dharwad, by obtaining due permission from the authority.

All research experiments on wheat carried out in both laboratory and greenhouse conditions in the present investigation strictly followed the guidelines of the University of Agricultural Sciences, Dharwad, Karnataka, India.

Received: 14 January 2021; Accepted: 15 July 2021

Published online: 27 July 2021

\section{References}

1. Raff, M. C. Size control: The regulation of cell numbers in animal development. Cell 86, 173-175 (1996).

2. Merkys, A. \& Laurinavicius, R. Development of higher plants under altered gravitational conditions. Adv. Space Biol. Med. 1, 155-181 (1991).

3. Brown, A. H. Gravity and the organism to gravity and the cell. Microgravity Sci. Technol. 4, 7-18 (1991).

4. Hateley, S., Hosamani, R., Bhardwaj, S. R., Pachter, L. \& Bhattacharya, S. Transcriptomic response of Drosophila melanogaster pupae developed in hypergravity. Genomics 108(3-4), 158-167 (2016).

5. Gilbert, R. et al. Spaceflight and simulated microgravity conditions increase virulence of Serratia marcescens in the Drosophila melanogaster infection model. NPJ Microgravity 6(1), 1-9 (2020).

6. Sathasivam, M., Hosamani, R., Swamy, B. K. \& Sreejalekshmi, K. G. Plant responses to real and simulated microgravity. Life Sci. Space Res. 28, 74-86 (2021).

7. Dai, K. et al. Effects of microgravity and hypergravity on platelet functions. J. Thromb. Haemost. 101, 902-910 (2009).

8. Santos, M. A. et al. Effect of hypergravity simulation on carrot germination and growth. Aviat. Space Environ. Med. 83, 1011-1012 (2012).

9. Santos, M. A., Russomano, T., Fachel, F. N. H., Cassel, E. \& Astarita, L. V. The effect of hypergravity on the germination and growth of Eruca sativa Mill. Online J. Sci. Technol. 2(3), 57-60 (2012).

10. Takemura, K. et al. A hypergravity environment increases chloroplast size, photosynthesis, and plant growth in the moss Physcomitrella patens. J. Plant Res. 130, 181-192 (2017).

11. Scherer, G. F. E. Halotolerance is enhanced in carrot callus by sensing hypergravity: Influence of calcium modulators and cytochalasin D. Protoplasma 229, 149-154 (2006).

12. Waldron, K. W. \& Brett, C. T. Effects of extreme acceleration on the germination, growth and cell wall composition of pea epicotyls. J. Expt. Bot. 41, 71-77 (1990).

13. Hoson, T. et al. Effects of hypergravity on growth and cell wall properties of cress hypocotyls. J. Exp. Bot. 47, 513-517 (1996).

14. Soga, K., Wakabayashi, K. \& Hoson, T. Hypergravity increases the molecular size of xyloglucans by decreasing xyloglucan-degrading activity in azuki bean epicotyls. Plant Cell Physiol. 40, 581-585 (1999).

15. Sagar, S. J. \& Pandit, B. V. Effect of hypergravity $(g)$ values on growth and chlorophyll content in wheat. Int. J. Integr. Biol. 9(3), 128 (2010).

16. Pandit, B. V., Sagar, J., Amit, N., Santosh, B. \& Vishakha, H. Effects of hypergravity on the chlorophyll content and growth of root and shoot during development in rice plants. In Photosynthesis. Energy from the Sun (eds Allen, J. F. et al.) 1599-1602 (Springer, 2008). 
17. Dixit, J. P., Jagtap, S. S., Kamble, S. M. \& Vidyasagar, P. B. Effects of short-term hypergravity exposure are reversible in Triticum aestivum L. caryopses. Microgravity Sci. Technol. 29, 343-350 (2017).

18. Mshelmbula, B. \& Akomolafe, G. Preliminary investigation on the effect of centrifugal force on germination and early growth of maize (Zea mays L.). Trans. Sci. Technol. 6(4), 328-333 (2019).

19. Kleine-Vehn, J. et al. Gravity-induced PIN transcytosis for polarization of auxin fluxes in gravity-sensing root cells. PNAS 107(51), 22344-22349 (2010).

20. Rakusová, H. et al. Polarization of PIN3-dependent auxin transport for hypocotyl gravitropic response in Arabidopsis thaliana. Plant J. 67(5), 817-826 (2011).

21. Ruiz Rosquete, M., Waidmann, S. \& Kleine-Vehn, J. PIN7 auxin carrier has a preferential role in terminating radial root expansion in Arabidopsis thaliana. Int. J. Mol. Sci. 19, 1238 (2018).

22. Soga, K., Wakabayashi, K., Kamisaka, S. \& Hoson, T. Gravity resistance in plants. Biol. Sci. Space 24, 129-134 (2010).

23. Wakabayashi, K., Soga, K., Kamisaka, S. \& Hoson, T. Changes in levels of cell wall constituents in wheat seedlings grown under continuous hypergravity conditions. Adv. Space Res. 36, 1292-1297 (2005).

24. Soga, K., Wakabayashi, K., Kamisaka, S. \& Hoson, T. Hypergravity inhibits elongation growth of azuki bean epicotyls independently of the direction of stimuli. Adv. Space Res. 36, 1269-1276 (2005).

25. Jagtap, S. S. \& Vidyasagar, P. B. Effects of high gravity $(g)$ values on growth and chlorophyll content in wheat. Int. J. Integr. Biol. 9, $128-130$ (2010).

26. Kiss, J. Z. Mechanisms of the early phases of plant gravitropism. Crit. Rev. Plant Sci. 19, 551-573 (2000).

27. Volkmann, D., Winnborner, U. \& Waberzeck, K. Graviresponsiveness of cress seedlings and structural status of presumptive statocytes from the hypocotyl. J. Plant Physiol. 142, 710-716 (1993).

28. Driss-ecole, D., Jeune, B., Prouteau, M., Julianus, P. \& Perbal, G. Lentil root statoliths reach a stable state in microgravity. Planta 211, 396-405 (2000).

29. Pfeifer, J., Kirchgessner, N., Colombi, T. \& Walter, A. Rapid phenotyping of crop root systems in undisturbed field soils using X-ray computed tomography. Plant Methods 11, 41 (2015).

30. Kaur, L., Gupta, A. K. \& Zhawar, V. K. ABA improvement of antioxidant metabolism under water stress in two wheat cultivars contrasting in drought tolerance. Indian J. Plant Physiol. 19, 189-196 (2014).

31. Wasaya, A., Zhang, X., Fang, Q. \& Yan, Z. Root phenotyping for drought tolerance: A review. Agronomy 8, 241 (2018).

32. Zaveri, E. \& Lobell, D. B. The role of irrigation in changing wheat yields and heat sensitivity in India. Nature 10, 41-44 (2019).

33. Nunes, A. C. P., Santos, G. A., Santos, M. A., Russomano, T. \& Resende, M. D. Application of hypergravity in Eucalyptus and Corymbia seeds. Cienc. Rural. 48, 4-12 (2018).

34. Pandit, B. V., Sagar, S. J., Jyotsana, P. D., Shailendra, M. K. \& Aarti, P. D. Effects of short-term hypergravity exposure on germination, growth and photosynthesis of Triticum aestivum L.. Microgravity Sci. Technol. 26(6), 375-384 (2014).

35. Wrigley, C. W. \& Shepherd, K. W. Electro-focusing of grain proteins from wheat genotypes. Annu. Acad. Sci. 209, 154-162 (1973).

36. Elena, K. P., Daniela, C. \& Mirosalar, O. Study of wheat protein degradation during germination. J. Microbiol. Biotechnol. Food Sci. 1(6), 1439-1447 (2012).

37. Bottari, A., Capocchi, A., Fontanini, D. \& Galleschi, I. Major proteinase hydrolyzing gliadin during wheat germination. Phytochemistry 43, 39-44 (1996).

38. Marumo, S. Auxins. In Chemistry of Plant Hormones (ed. Takahashi, N.) 9-56 (CRC Press, 1986).

39. Epstein, E. \& Ludwig-Muller, J. Indole-3-butyric acid in plants: Occurrence, biosynthesis, metabolism, and transport. Physiol. Plant 88, 382-389 (1993).

40. Marumo, S., Hattori, H. \& Munakata, K. Isolation of 4-Chloroindolyl-3-acetic acid from immature seeds of Pisum sativum. Nature 219, 959-960 (1968).

41. Pilet, P. E. \& Saugy, M. Effect on root growth of endogenous and applied IAA and ABA: A critical re-examination. Plant Physiol. 83, 33-38 (1987).

42. Frick, E. M. \& Strader, L. C. Roles for IBA-derived auxin in plant development. J. Exp. Bot. 69, 169-177 (2018).

43. Mega, R. et al. Sustained low abscisic acid levels increase seedling vigor under cold stress in rice (Oryza sativa L.). Sci. Rep. 5, 813-829 (2015).

44. Hansen, H. \& Dorffling, K. Root-derived trans-zeatin riboside and abscisic acid in drought-stressed and rewatered sunflower plants: Interaction in the control of leaf diffusive resistance? Funct. Plant Biol. 30, 25-39 (2003).

45. Vieira, A. R., Vieira, M. D. G. C. C., Fraga, A. C., Oliviera, J. A. \& Santos, C. D. D. Action of gibberellic acid (GA3) on dormancy and activity of $\alpha$-amylase in rice seeds. Rev. Bras. Sementes 24, 43-48 (2002).

46. Inada, S. \& Shimmen, T. Regulation of elongation growth by gibberellin in root segments of Lemna minor. Plant Cell Physiol. 41(8), 932-939 (2000).

47. Desgagné-Penix, I. \& Sponsel, V. M. Expression of gibberellin 20-oxidase1 (AtGA20ox1) in Arabidopsis seedlings with altered auxin status is regulated at multiple levels. J. Exp. Bot. 59(8), 2057-2070 (2008).

48. Ubeda-Tomás, S. et al. Root growth in Arabidopsis requires gibberellin/DELLA signalling in the endodermis. Nat. Cell Biol. 10, 625-628 (2008).

49. Ubeda-Tomas, S. et al. Gibberellin signaling in the endodermis controls Arabidopsis root meristem size. Curr. Biol. 19(14), 11941199 (2009).

50. Tanimoto, E. Tall or short? Slender or thick? A plant strategy for regulating elongation growth of roots by low concentrations of gibberellin. Ann. Bot. 110(2), 373-381 (2012).

51. Raya-González, J., Pelagio-Flores, R. \& López-Bucio, J. The jasmonate receptor COI1 plays a role in jasmonate-induced lateral root formation and lateral root positioning in Arabidopsis thaliana. J. Plant Physiol. 169, 1348-1358 (2012).

52. Gasperini, D. et al. Multilayered organization of jasmonate signalling in the regulation of root growth. PLoS Genet. 11, e1005300 (2015).

53. Tung, P., Hooker, T. S., Tampe, P. A., Reid, D. M. \& Thorpe, T. A. Jasmonic acid: Effects on growth and development of isolated tomato roots cultured in-vitro. Int. J. Plant Sci. 157, 713-721 (1996).

54. Corti-Monzon, G., Pinedo, M., Lamattina, L. \& Canal, L. Sunflower root growth regulation: The role of jasmonic acid and its relation with auxins. Plant Growth Regul. 66, 129-136 (2012).

55. Pigolev, A., Miroshnichenko, D., Dolgov, S. \& Savchenko, T. Regulation of sixth seminal root formation by jasmonate in Triticum aestivum L.. Plants 10, 219 (2021).

56. Zhou, W. et al. A jasmonate signaling network activates root stem cells and promotes regeneration. Cell 177, $942-956$ (2019).

57. Armengot, L. et al. Functional interplay between protein kinase CK2 and salicylic acid sustains PIN transcriptional expression and root development. Plant J. 78, 411-423 (2014).

58. Agtuca, B. et al. Carbon-11 reveals opposing roles of auxin and salicylic acid in regulating leaf physiology, leaf metabolism, and resource allocation patterns that impact root growth in Zea mays. J. Plant Growth Regul. 33, 328-339 (2013).

59. Gutiérrez-Coronado, M. A., Trejo-López, C. \& Larqué-Saavedra, A. Effects of salicylic acid on the growth of roots and shoots in soybean. Plant Physiol. Biochem. 36, 563-565 (1998).

60. Siddiqi, K. S. \& Husen, A. Plant response to jasmonates: Current developments and their role in changing environment. Bull. Natl. Res. Centre 43, 153 (2019). 
61. Kozeko, L. \& Kordyum, E. Effect of hypergravity on the level of heat shock proteins 70 and 90 in pea seedlings. Microgravity Sci. Technol 21, 175-178 (2009).

62. Qin, H. et al. Regulated expression of an isopentenyl transferase gene (IPT) in peanut significantly improves drought tolerance and increases yield under field conditions. Plant. Cell Physiol. 52, 1904-1914 (2011).

63. Van Loon, J. J. W. A., Krause, J. \& Cunha, H. The large diameter centrifuge, LDC, for life and physical sciences and technology. In Proc. 'Life in Space for Life on Earth Symposium', Angers, France 22-27 (2008) (ESA SP-663, December 2008).

64. Manzano, A. I., Herranz, R., van Loon, J. J. W. A. \& Medina, F. J. A Hypergravity environment induced by centrifugation alters plant cell proliferation and growth in an opposite way to microgravity. Microgravity Sci. Technol. 24, 373-381 (2012).

65. Ahmadvand, G., Soleimani, F., Saadatian, B. \& Pouya, M. Effects of seed priming on germination and emergence traits of two soybean cultivars under salinity stress. J. Basic Appl. Sci. Res. 3, 234-241 (2012).

66. Davies, R., Sacco, A. D. \& Newton, R. Germination testing: Procedures and evaluation. J. Basic Appl. Sci. Res. 1, 205-216 (2015).

67. Anonymous. International rules of seed testing. Seed Sci. Technol., 27, 25-30 (2013).

68. AOSA. Handbook on Seed Testing (Association of Official Seed Analysis, 1983).

69. Abdul-Baki, A. A. \& Anderson, J. O. Vigour determination of soybean seed by multiple criteria. Crop Sci. 13, 630-633 (1973).

70. Bruns, H. A. \& Croy, L. I. Root volume and root dry weight measuring system for wheat cultivars. Cereal Res. Commun. 13, 177-183 (1985).

71. Simpson, G. M. \& Naylor, J. M. Dormancy studies in seeds of Avena fatua: A relationship between maltase, amylases and gibberellins. Can. J. Bot. 40, 1659-1673 (1962).

72. Kittock, P. A. \& Law, A. G. Relationship of seedling vigor to respiration and tetrazolium chloride reduction of germinating wheat seeds. Agron. J. 60, 286-288 (1968).

73. Bames, J. D., Blauger, L., Manrique, E. \& Davison, A. W. A reappraisal of the use of DMSO for the extraction and determination of total chlorophyll in lichens and higher plants. Environ. Exp. Bot. 32, 85-100 (1992).

74. Pan, X., Welti, R. \& Wang, X. Simultaneous quantification of major phytohormones and related compounds in crude plant extracts by liquid chromatography-electrospray tandem mass spectrometry. Phytochemistry 69(8), 1773-1781 (2008).

75. Hurkman, W. J. \& Tanaka, C. K. Solubilization of plant membrane proteins for analysis by two-dimensional gel electrophoresis. Plant Physiol. 81(3), 802-806 (1986).

76. Bradford, M. M. A rapid and sensitive method for the quantitation of microgram quantities of protein utilizing the principle of protein-dye binding. Anal. Biochem. 72(1-2), 248-254 (1976).

77. Nowakowski, A., Wobig, W. J. \& Petering, D. H. SDS-PAGE: High-resolution electrophoretic separation of proteins with retention of native properties including bound metal ions. Metallomics 5, 1-33 (2014).

78. Kumar, N. \& Singh, M. Growth parameters and productivity of wheat as influenced by crop establishment methods and different seed rate. Int. J. Pure Appl. Biosci. 5(4), 2134-2140 (2017).

79. R Core Team (2020). R: A Language and Environment for Statistical Computing. (R Foundation for Statistical Computing, Vienna, Austria). http://www.R-project.org/. (Accessed 13 Oct 2020).

\section{Acknowledgements}

The first author (BKS) and Malarvizhi S (MS) acknowledge the DBT-JNU, Govt. of India for the fellowship. The corresponding author, Ravikumar Hosamani (RH) acknowledges DST-SERB for awarding research grant of which this publication is part. The authors also thank Prof. Ramesh Bhat for helping us with the Statistics using R-program.

\section{Author contributions}

R.H., B.K.S. and M.S. conceived the experiment, B.K.S. and M.S. conducted the experiment, B.K.S., M.S. and R.H. analyzed the results and written the manuscript. C.S.S., U.R.G. and N.M. edited the manuscript, and all authors reviewed the manuscript.

\section{Competing interests}

The authors declare no competing interests.

\section{Additional information}

Supplementary Information The online version contains supplementary material available at https://doi.org/ 10.1038/s41598-021-94771-8.

Correspondence and requests for materials should be addressed to R.H.

Reprints and permissions information is available at www.nature.com/reprints.

Publisher's note Springer Nature remains neutral with regard to jurisdictional claims in published maps and institutional affiliations.

(c) (i) Open Access This article is licensed under a Creative Commons Attribution 4.0 International cc) License, which permits use, sharing, adaptation, distribution and reproduction in any medium or format, as long as you give appropriate credit to the original author(s) and the source, provide a link to the Creative Commons licence, and indicate if changes were made. The images or other third party material in this article are included in the article's Creative Commons licence, unless indicated otherwise in a credit line to the material. If material is not included in the article's Creative Commons licence and your intended use is not permitted by statutory regulation or exceeds the permitted use, you will need to obtain permission directly from the copyright holder. To view a copy of this licence, visit http://creativecommons.org/licenses/by/4.0/.

(C) The Author(s) 2021 